\title{
WELDED ALUMINUM ALLOY PLATE GIRDERS SUBJECTED TO SHEAR FORCE
}

\author{
Feng Zhou ${ }^{1 \mathrm{a}, 1 \mathrm{~b}}$, Ben Young ${ }^{2, *}$ and Hin-Chung Lam ${ }^{3}$ \\ ${ }^{I a}$ Department of Building Engineering, Tongji University, 1239 Siping Road, Shanghai 200092, China \\ ${ }^{1 b}$ State Key Laboratory of Disaster Reduction in Civil Engineering, Shanghai 200092, China \\ ${ }^{2}$ Department of Civil Engineering, The University of Hong Kong, Pokfulam Road, Hong Kong, China \\ ${ }^{3}$ Katech International Ltd., Hung To Road, Kwun Tong, Hong Kong, China \\ *(Corresponding author: E-mail: young@hku.hk)
}

Received: 2 June 2011; Revised: 10 June 2011; Accepted: 16 June 2011

\begin{abstract}
Numerical investigation of aluminum alloy plate girders subjected to shear force has been presented in this paper. The aluminum alloy plate girders were fabricated by welding three plates to form an I-section. A total of 118 numerical data are presented. A non-linear finite element model is developed and verified against experimental results. Geometric and material non-linearities were included in the finite element model. The welding of the aluminum alloy plate girders and the influence of the heat affected zone (HAZ) are also considered and carefully modeled. A sensitivity analysis on geometric imperfections of the aluminum alloy plate girders was performed. It was shown that the finite element model closely predicted the ultimate loads, web deformations and failure modes of aluminum alloy plate girders. Hence, the model was used for an extensive parametric study of cross-section geometries, and the web slenderness value ranged from 49 to 393 . The test results and the shear resistances predicted by the finite element analysis were compared with the design strengths obtained using the European Code and American Specification for aluminum structures. Based on the experimental and numerical results, a design method for shear resistance of aluminum alloy plate girders is proposed in this study. The proposed design method is modified from the design rules in the EC9 Code. It is shown that the proposed design strengths are generally conservative and reliable.
\end{abstract}

Keywords: Aluminum structures, Design rules, Numerical investigation, Plate girder, Sensitivity analysis, Shear resistance

\section{INTRODUCTION}

In the past years, structural members in the form of plate girders have been widely used in the construction of buildings, bridges and other structures. They are popular to be used by designers since they can be tailor-made to suit any situation whereas hot-rolled steel sections are only rolled in a limited number of profiles. It should be noted that plate girders can also be fabricated from aluminum alloy. Aluminum alloy is much lighter than steel and sometimes it may be very useful for design of structures where the self-weight is an important design criterion. In addition, the nature of aluminum alloy would not normally rust so the maintenance of an aluminum structure is minimal and as a result of considerable cost-saving. Therefore, aluminum alloy plate girders have certain advantages over steel plate girders and should be investigated to gain a better understanding of their behaviour.

The webs of aluminum alloy plate girders are usually slender, hence, easy to buckle in shear at relative low applied loads. In order to provide an efficient and economical design, advantage should be taken of the post-buckling capacity of the plate girder. It has been well-documented by Evans [1] that a transversely stiffened girder can withstand loads considerably in excess of the load at which web buckling first occurs. This post-buckling reserve of strength arises from the development of tension field action within the web.

The post-buckling behaviour of steel plate girder has been studied by many researchers [2-6]. However, a comparatively little research has been conducted on aluminum alloy plate girders subjected to shear force. Evans and Hamoodi [7] performed twenty-two tests to investigate the 
post-buckling behaviour of welded aluminum alloy plate girders. The girders have transverse or longitudinal web stiffeners and are subjected to different combinations of shear and bending loads. It was observed that, although shear sway mechanisms similar to those for steel girders was developed, the webs of aluminum girders may fracture in the heat affected zones (HAZ) adjacent to the welds. It is shown that the tension field theory, originally developed for steel girders, may overestimate the shear-carrying capacity of aluminum girders and it is concluded that the theory requires some modification before it can be applied with confidence to aluminum girders. Based on these experimental results, a finite element model was developed by Cheng et al. [8] to investigate the shear resistance of aluminum alloy plate girders. However, the welding of the aluminum alloy plate girder is not considered. Hence, the influence of the heat affected zone (HAZ) is ignored. It should be noted that heating the material tends to erase the effect of precipitation-heat treatments and strain-hardening, so arc welding, which brings a localized portion of the metal to the melting point, decreases the material's strength at the weld [9].

The objective of this paper is to assess the appropriateness of the shear resistance design rules in the current specifications for aluminum alloy plate girders. An accurate finite element model (FEM) was developed to investigate the behaviour of aluminum alloy plate girders subjected to shear force. The finite element analysis (FEA) program ABAQUS [10] was used for the numerical investigation. The FEM included geometric and material non-linearities. The welding of the aluminum alloy plate girder and the influence of the heat affected zone (HAZ) are considered and carefully modeled. The FEM was verified against the aluminum alloy plate girder tests conducted by Lam [11]. Aluminum alloy plate girders with end posts (web stiffeners) consist of a single plate were investigated. Parametric study was performed to investigate the effect of cross-section geometries on the shear resistance of aluminum alloy plate girder. The test results as well as the shear resistances predicted by the FEA were compared with the design strengths obtained using the European Code [12] and American Specification [13] for aluminum structures. Modifications on the design rules of EC9 [12] Code are made for the proposed design method for shear resistance of aluminum alloy plate girders with end posts.

\section{SUMMARY OF EXPERIMENTAL INVESTIGATION}

A test program has been conducted by Lam [11] to investigate the shear behaviour of aluminum alloy plate girders with end posts consisting of a single plate. A total of eight tests of 7020 series and 6082 series aluminum alloy plate girders have been conducted. Both series of 7020 and 6082 aluminum alloy plate girders consist of two panels of equal depth for each specimen. At mid-span between the panels of each girder, a very strong intermediate doubled-sided vertical stiffener was used. Each panel comprised two equal flanges of rectangular cross-section, a rectangular web plate of uniform thickness and an end post consisting of a single plate. The layout and the definition of symbols for an aluminum alloy plate girder are shown in Figure 1. The dimensions and material properties are shown in Table 1.

Prior to testing, one of the panels of the girder was reinforced while the other panel was instrumented for testing. The girder was simply supported at its ends and subjected to a vertical point load which was applied by a servo-controlled hydraulic jack. Each girder was loaded predominantly in shear. During the tests, two different failure modes were observed. The collapse behaviour of the test II-7020 and test II-6082 are similar, but entirely different from the other tests. The failure modes observed for most of the aluminum alloy plate girders of test I, test III and test IV of both series of 7020 and 6082 were mainly shear buckling. Figure 2a shows the failure mode of the test I-7020. The aluminum alloy plate girders failed by buckling in the end post for test II-7020 and test II-6082, as clearly shown in Figure 3a. The severe deformation of the failed end 
post can be seen in Figure 3a. In addition to the buckling of the end post, which occurred at a position of about one-third of the height of the post, the web panel has also buckled. The ultimate loads of the aluminum alloy plate girder tests are shown in Table 2. The experimental investigation is detailed in Lam [11].

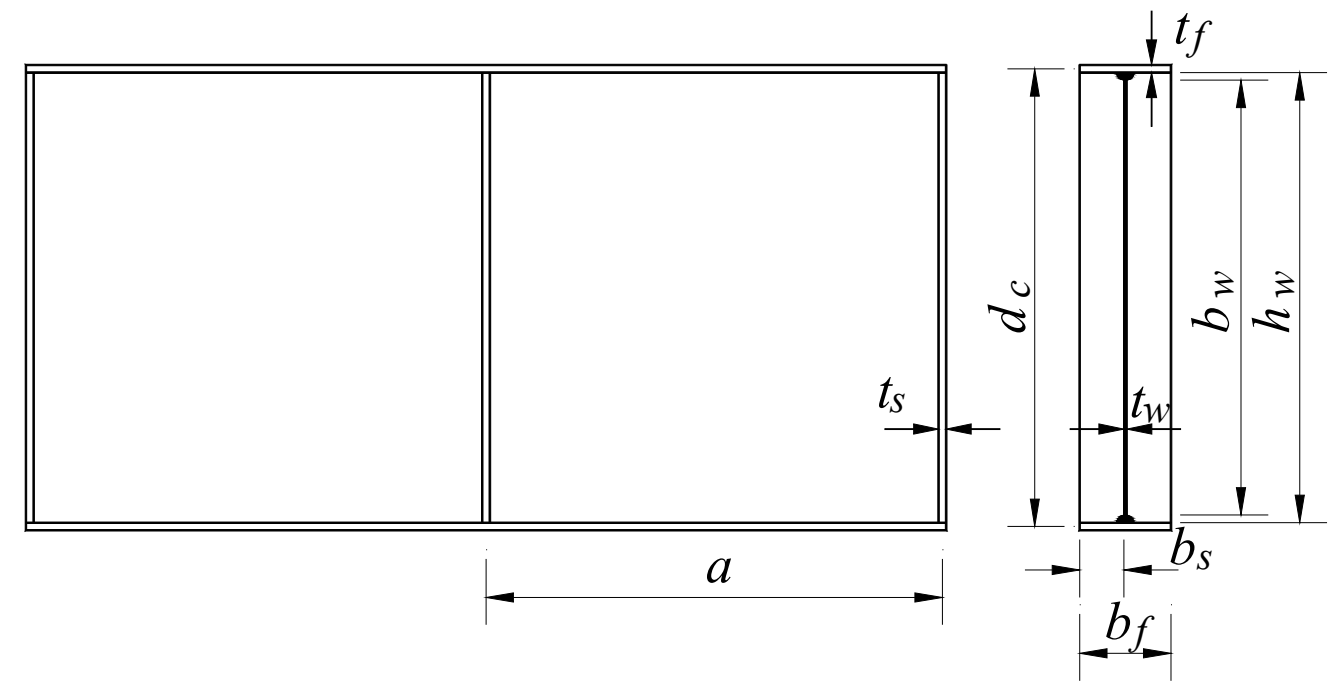

(a) Front view

(b) End view

Figure 1. Definition of Symbols

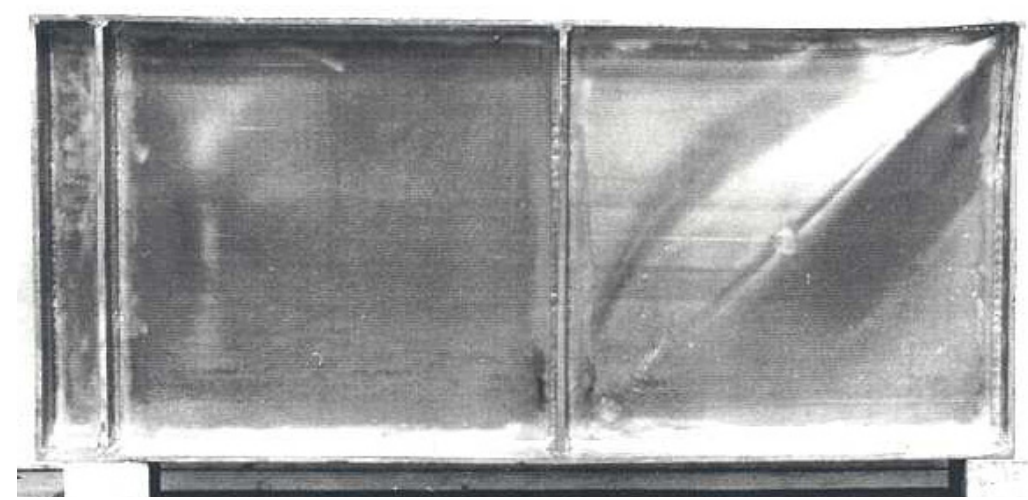

(a) Experiment (Lam 1993)

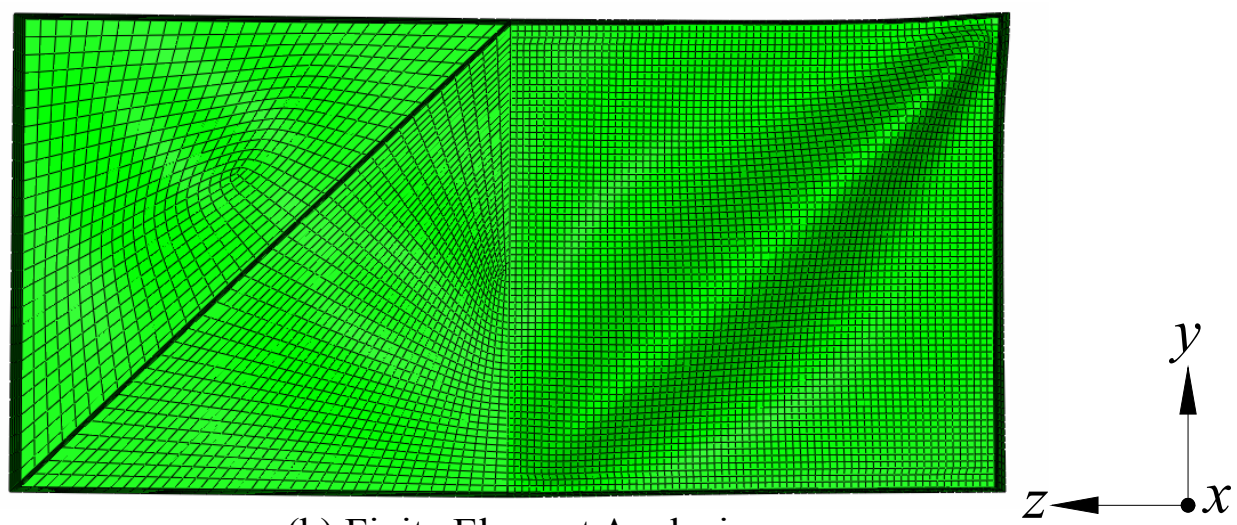

(b) Finite Element Analysis

Figure 2. Comparison of Experimental and Numerical Failure Mode of Specimen Test I -7020 


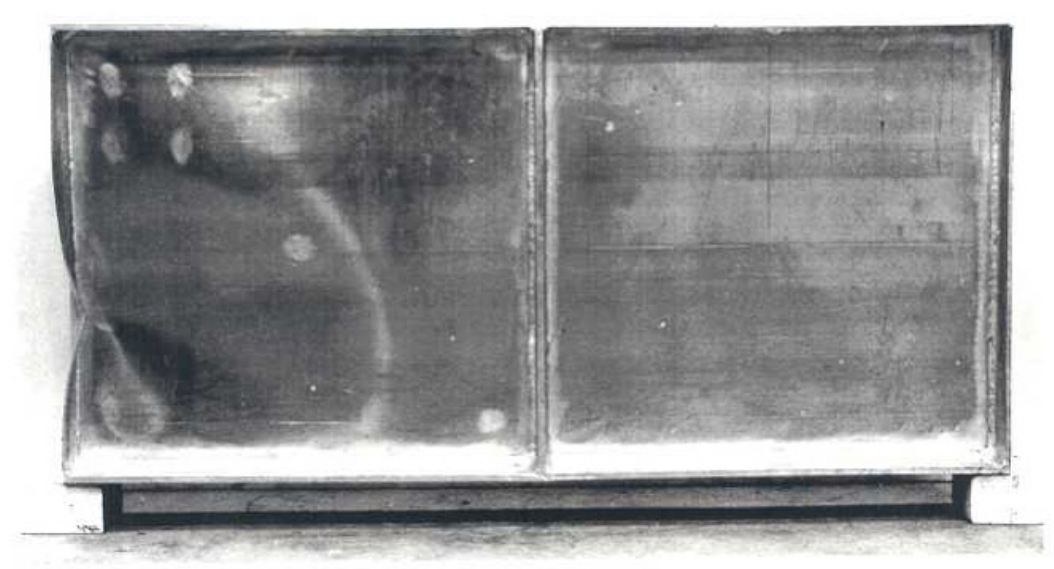

(a) Experiment (Lam 1993)

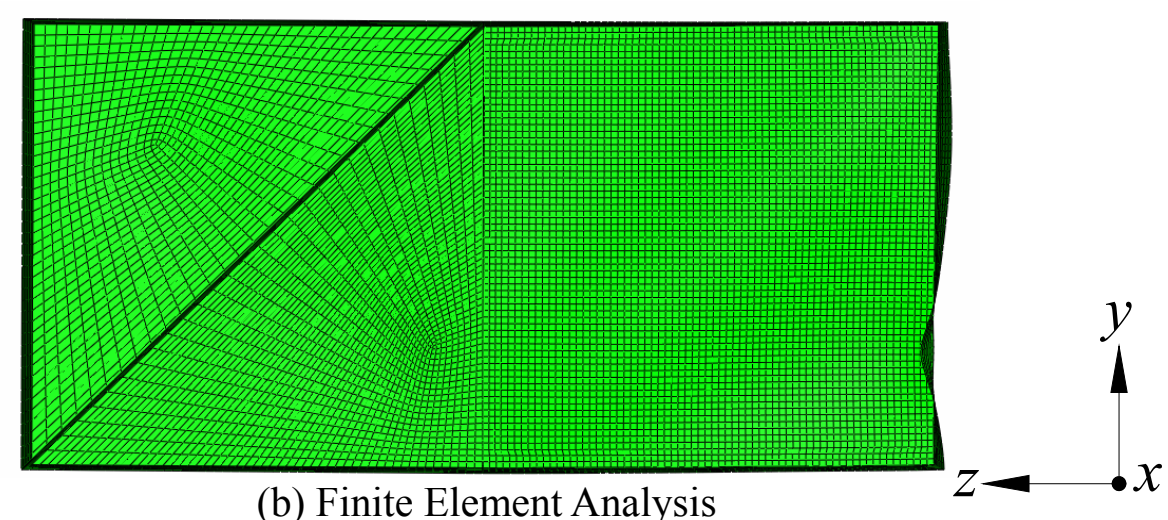

(b) Finite Element Analysis

Figure 3. Comparison of Experimental and Numerical Failure Mode of Specimen Test II -7020

Table 1. Dimensions and Material Properties of Test Specimens (Lam 1993)

\begin{tabular}{|c|c|c|c|c|c|c|c|c|c|c|c|c|}
\hline \multirow{3}{*}{ Specimen } & \multirow{3}{*}{ Series } & \multicolumn{3}{|c|}{ Web } & \multirow{2}{*}{$\begin{array}{c}\text { Space } \\
a\end{array}$} & \multicolumn{3}{|c|}{ Flange } & \multicolumn{3}{|c|}{ Stiffener } & \multirow{2}{*}{$\begin{array}{c}\begin{array}{c}\text { Young's } \\
\text { modulus }\end{array} \\
E\end{array}$} \\
\hline & & $h_{w}$ & $t_{w}$ & $f_{w}$ & & $b_{f}$ & $t_{f}$ & $f_{f}$ & $b_{s}$ & $t_{s}$ & $f_{s}$ & \\
\hline & & $(\mathrm{mm})$ & $(\mathrm{mm})$ & $(\mathrm{MPa})$ & $(\mathrm{mm})$ & $(\mathrm{mm})$ & $(\mathrm{mm})$ & $\begin{array}{c}\text { (MPa } \\
\text { ) }\end{array}$ & $(\mathrm{mm})$ & $(\mathrm{mm})$ & (MPa) & (MPa) \\
\hline Test I & \multirow{4}{*}{7020} & 601.0 & 3.15 & 334.1 & 633.2 & 129.5 & 9.85 & 341.6 & 64.4 & 9.65 & 341.6 & 70400 \\
\hline Test II & & 598.5 & 3.15 & 334.1 & 630.7 & 128.7 & 9.70 & 341.6 & 64.5 & 3.15 & 334.1 & 70300 \\
\hline Test III & & 598.5 & 3.15 & 334.1 & 632.3 & 129.0 & 9.69 & 341.6 & 65.1 & 6.26 & 317.4 & 70333 \\
\hline Test IV & & 601.0 & 3.15 & 334.1 & 633.3 & 129.6 & 9.84 & 341.6 & 55.0 & 9.55 & 341.6 & 70400 \\
\hline Test I & \multirow{4}{*}{6082} & 602.0 & 3.18 & 245.1 & 632.8 & 129.0 & 9.74 & 272.5 & 64.4 & 9.80 & 272.5 & 70000 \\
\hline Test II & & 600.0 & 3.18 & 245.1 & 630.6 & 129.0 & 9.80 & 272.5 & 63.7 & 3.22 & 245.1 & 70000 \\
\hline Test III & & 600.0 & 3.18 & 245.1 & 631.1 & 129.0 & 9.80 & 272.5 & 64.0 & 6.43 & 278.4 & 70000 \\
\hline Test IV & & 602.0 & 3.18 & 245.1 & 635.3 & 129.0 & 9.74 & 272.5 & 54.5 & 9.80 & 272.5 & 70000 \\
\hline
\end{tabular}

Note: $b_{s}$ shown above is actually half of the $b_{s}$ shown in the experiments conducted by Lam (1993) 
Table 2. Comparison of Numerical Results with Test Results

\begin{tabular}{|c|c|c|c|c|c|c|c|c|}
\hline \multirow{3}{*}{ Specimen } & \multirow{3}{*}{ Series } & $\begin{array}{l}\text { Exp. load } \\
\text { per web }\end{array}$ & \multicolumn{6}{|c|}{ Comparison } \\
\hline & & $V_{E x p}$ & \multicolumn{6}{|c|}{$V_{E x p} / V_{F E A}$} \\
\hline & & $(\mathrm{kN})$ & $h_{w} / 100$ & $h_{w} / 200$ & $h_{w} / 500$ & $h_{w} / 1000$ & $h_{w} / 3000$ & $h_{w} / 6000$ \\
\hline Test I & \multirow{4}{*}{7020} & 157.0 & 1.00 & 0.99 & 0.98 & 0.97 & 0.97 & 0.97 \\
\hline Test II & & 118.5 & 1.07 & 1.04 & 1.03 & 1.03 & 1.03 & 1.03 \\
\hline Test III & & 152.0 & 1.05 & 1.04 & 1.04 & 1.03 & 1.03 & 1.03 \\
\hline Test IV & & 156.8 & 0.96 & 0.97 & 0.97 & 0.98 & 0.98 & 0.98 \\
\hline Test I & \multirow{4}{*}{6082} & 119.0 & 0.93 & 0.94 & 0.94 & 0.94 & 0.94 & 0.94 \\
\hline Test II & & 84.5 & 1.00 & 0.99 & 0.98 & 0.98 & 0.98 & 0.98 \\
\hline Test III & & 113.5 & 0.97 & 0.98 & 0.98 & 0.98 & 0.98 & 0.98 \\
\hline \multirow[t]{3}{*}{ Test IV } & & 134.5 & 1.05 & 1.06 & 1.07 & 1.08 & 1.08 & 1.08 \\
\hline & & Mean & 1.004 & 1.001 & 0.999 & 0.999 & 0.999 & 0.999 \\
\hline & & COV & 0.049 & 0.041 & 0.043 & 0.045 & 0.045 & 0.045 \\
\hline
\end{tabular}

\section{NUMERICAL INVESTIGATION}

\subsection{General}

The non-linear finite element analysis program ABAQUS [10] version 6.7 was used to simulate the ultimate loads, web deformations and failure modes of aluminum alloy plate girders with end posts. The finite element simulation consisted of two steps. The first step is linear perturbation analysis, which was performed on a "perfect" geometry to obtain probable elastic buckling modes of the aluminum alloy plate girder. The second step is non-linear analysis by incorporating both geometric and material non-linearities, which was performed to obtain the ultimate load, web deformation and failure mode of the aluminum alloy plate girder.

In the finite element model (FEM), the measured cross-section dimensions, material properties obtained from coupon tests and initial geometric imperfections were used. The model was based on the centerline dimensions of the cross-sections. The welding of the aluminum alloy plate girder and the influence of the heat affected zone (HAZ) were considered and carefully modeled.

\subsection{Element Type and Mesh}

The four-node doubly curved general-purpose shell elements S4R were used in the finite element analysis (FEA) to model the aluminium alloy plate girder components. It is mentioned in the ABAQUS manual that S4R element is suitable for complex buckling behaviour. The S4R element has six degrees of freedom per node and provides accurate solutions to most applications [10]. Five integration points were taken in the thickness direction. The finite element mesh used in the model was investigated by varying the size of the elements in the cross-section to provide both accurate results and less computational time. The finer mesh size of $8 \times 8 \mathrm{~mm}$ (length by width) in the HAZ areas and the finite element mesh size of $15 \times 15 \mathrm{~mm}$ for the rest of the section were used. Figures $2 b$ and $3 \mathrm{~b}$ show the geometry and the mesh of the plate girders. 


\subsection{Boundary Condition and Method of Loading}

The aluminum alloy plate girder was simply supported at its end and subjected to a vertical point load. Following the test procedure, the simply supported end boundary conditions were modeled by restraining the translational degrees of freedom in the $\mathrm{Y}$ and $\mathrm{Z}$ directions at one end and restraining the translational degree of freedom in the $\mathrm{Y}$ direction only at the other end.

The loading method used in the FEA was identical to that used in the tests. The displacement control method was used for the analysis of the aluminum alloy plate girder. Vertical point load was applied to the girder by specifying a displacement to the nodes at the center of the girder.

\subsection{Material Modelling}

As mentioned earlier, the first step of the FEA is a linear analysis where there is a linear relationship between the applied loads and the response of the structure. In this step, the stiffness of the structure remained constant. Hence, only the density, Young's modulus and Poisson's ratio defined the material properties. However, the second step of the FEA is a non-linearity analysis where the stiffness of the structure changed as it deformed. The material non-linearity was incorporated in the FEM by specifying the true values of stresses and strains. The plasticity of the material was simulated by a mathematical model, known as the incremental plasticity model, and the true stress $\left(\sigma_{\text {true }}\right)$ and plastic true strain $\left(\varepsilon_{\text {true }}^{p l}\right)$ were specified in ABAQUS [10].

It is well-known that a heat affected zone (HAZ) develops in an aluminum alloy plate girder adjacent to the welds. In the HAZ, the strength varies from a minimum at the weld to the full strength of the virgin material at a certain distance away from the weld. The welding of the aluminum alloy plate girder and the influence of the heat affected zone (HAZ) are also considered and carefully modeled in this study. The extent of the HAZ and material properties of the HAZ are predicted according to EC9 Code [12], then modeled accordingly in the FEM.

\section{SENSITIVITY ANALYSIS AND VERIFICATION OF FINITE ELEMENT MODEL}

A sensitivity analysis on geometric imperfections of the aluminum alloy plate girders was performed for both series of 7020 and 6082 to determine the most appropriate scale factor for the finite element model (FEM). A number of scale factors expressed in terms of 1/100, 1/200, 1/500, $1 / 1000,1 / 3000$ and $1 / 6000$ of the depth of the web between the flanges $\left(h_{w}\right)$ were investigated. The results of the sensitivity analysis are shown in Table 2 , in which, $V_{E x p}$ is the experimental ultimate load, and $V_{F E A}$ is the ultimate load predicted by the FEA. It is shown that using the scale factors of $1 / 100,1 / 200,1 / 500,1 / 1000,1 / 3000$ and $1 / 6000$ of the depth of the web between the flanges $\left(h_{w}\right)$ provide good predictions compared with the experimental results. The results obtained for different scale factors are relatively close. Generally, the scale factor of $1 / 200$ of the depth of the web between the flanges provides the best predictions for both series of 7020 and 6082 in terms of the mean value and coefficient of variation (COV). Hence, a scale factor of $h_{w} / 200$ was chosen for the verification of the finite element model as well as for the parametric study.

In the verification of the developed FEM, a total of eight aluminum alloy plate girders subjected to shear force were analyzed. A comparison between the experimental results and the finite element results was carried out. The main objective of this comparison is to verify and check the accuracy of the finite element model. The comparison of the test results $\left(V_{E x p}\right)$ with the shear resistance of aluminum alloy plate girders $\left(V_{F E A}\right)$ predicted by the FEA is shown in Table 2 . It can be seen that good agreement has been achieved between both results for all specimens where a scale factor of 
$1 / 200$ of the depth of the web between the flanges was used in modeling the geometric imperfections of the aluminum alloy plate girders. A maximum difference of $6 \%$ was observed between the experimental and numerical results for specimens Test I-6082 and Test IV-6082. The mean value of the $V_{E x p} / V_{F E A}$ ratio is 1.001 with the corresponding coefficient of variation $(\mathrm{COV})$ of 0.041 .

Two different failure modes were observed from the tests and also verified by the finite element model, as shown in Figures 2 and 3. The failure mode of the tests II-7020 and test II-6082 is entirely different from the other tests as mentioned in the Summary of Experimental Investigation Section. A typical comparison of the load-web deformation curves between experimental and finite element analysis for specimen test I-7020 is shown in Figure 4. It is shown that both the failure modes and the load-web deformation curves reflect good agreement between the experimental and finite element results.

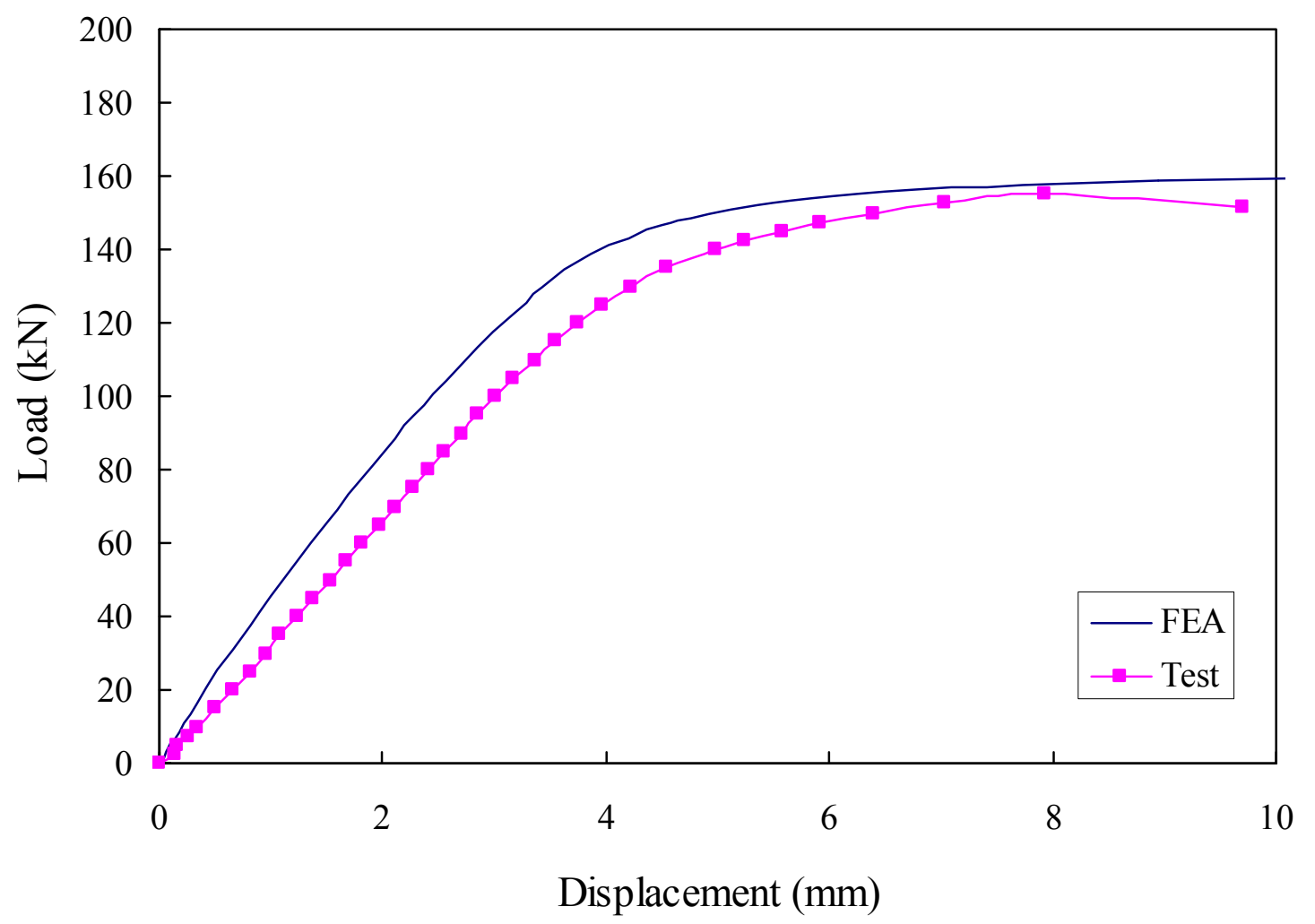

Figure 4. Comparison of Experimental and Numerical Load-web Deformation Curves for Specimen Test I - 7020

\section{PARAMETRIC STUDY}

It is shown that the FEM closely predicted the shear behaviour of aluminum alloy plate girders with end posts consisting of a single plate. Hence, parametric study was carried out to study the effects of cross-section geometries on the shear ultimate load of aluminum alloy plate girder. A total of 118 specimens in 4 Groups were analyzed in the parametric study. In Group 1, 35 specimens were analyzed to investigate the effects of web on the shear behaviour of aluminum alloy plate girder. The dimensions of web varied and the web slenderness $\left(h_{w} / t_{w}\right)$ ranged from 98 to 393 while the dimensions of flange and stiffener were kept constant, as shown in Table 3. Five different aspect ratios $\left(a / b_{w}\right)$ were investigated in this study. In Group 2, 40 specimens were analyzed to investigate the effects of bending rigidity of flange on the collapse behaviour of aluminum alloy plate girder. 
The dimensions of flange and web varied and four different flange-to-web thickness ratios $\left(t_{f} / t_{w}\right)$ of 2, 3, 4 and 5 were investigated, while the dimensions of stiffener were kept constant, as shown in Table 4. In Group 3, 36 specimens were analyzed to investigate the effects of bending rigidity of stiffener on the collapse behaviour of aluminum alloy plate girder. The dimensions of stiffener and web varied and four different stiffener-to-web thickness ratios $\left(t_{s} / t_{w}\right)$ of $2,3,4$ and 5 were investigated, while the dimensions of flange were kept constant, as shown in Table 5 . The half width of stiffener $\left(b_{s}\right)$ was also investigated in Group 4, as shown in Table 6, where 7 specimens with half width of stiffeners were analyzed. The material properties of test specimen of Test II-6082 were used in the parametric study.

Table 3. Cross-section Dimensions of Parametric Study for Group 1

\begin{tabular}{|c|c|c|c|c|c|c|c|c|c|}
\hline \multirow{3}{*}{ Specimen } & \multicolumn{3}{|c|}{ Web } & \multicolumn{2}{|c|}{ Space } & \multicolumn{2}{|c|}{ Flange } & \multicolumn{2}{|c|}{ Stiffener } \\
\hline & $d_{c}$ & $t_{w}$ & $h_{w} / t_{w}$ & $a$ & $a / b_{w}$ & $b_{f}$ & $t_{f}$ & $b_{s}$ & $t_{s}$ \\
\hline & $(\mathrm{mm})$ & $(\mathrm{mm})$ & & $(\mathrm{mm})$ & & $(\mathrm{mm})$ & $(\mathrm{mm})$ & $(\mathrm{mm})$ & $(\mathrm{mm})$ \\
\hline G1-T1.5-A0.5 & 600 & 1.5 & 393 & 300 & 0.56 & 200 & 10 & 100 & 10 \\
\hline G1-T1.5-A1.0 & 600 & 1.5 & 393 & 600 & 1.11 & 200 & 10 & 100 & 10 \\
\hline G1-T1.5-A2.0 & 600 & 1.5 & 393 & 1200 & 2.22 & 200 & 10 & 100 & 10 \\
\hline G1-T1.5-A3.0 & 600 & 1.5 & 393 & 1800 & 3.33 & 200 & 10 & 100 & 10 \\
\hline G1-T1.5-A4.0 & 600 & 1.5 & 393 & 2400 & 4.44 & 200 & 10 & 100 & 10 \\
\hline G1-T2.0-A0.5 & 600 & 2.0 & 295 & 300 & 0.56 & 200 & 10 & 100 & 10 \\
\hline G1-T2.0-A1.0 & 600 & 2.0 & 295 & 600 & 1.11 & 200 & 10 & 100 & 10 \\
\hline G1-T2.0-A2.0 & 600 & 2.0 & 295 & 1200 & 2.22 & 200 & 10 & 100 & 10 \\
\hline G1-T2.0-A3.0 & 600 & 2.0 & 295 & 1800 & 3.33 & 200 & 10 & 100 & 10 \\
\hline G1-T2.0-A4.0 & 600 & 2.0 & 295 & 2400 & 4.44 & 200 & 10 & 100 & 10 \\
\hline G1-T2.5-A0.5 & 600 & 2.5 & 236 & 300 & 0.56 & 200 & 10 & 100 & 10 \\
\hline G1-T2.5-A1.0 & 600 & 2.5 & 236 & 600 & 1.11 & 200 & 10 & 100 & 10 \\
\hline G1-T2.5-A2.0 & 600 & 2.5 & 236 & 1200 & 2.22 & 200 & 10 & 100 & 10 \\
\hline G1-T2.5-A3.0 & 600 & 2.5 & 236 & 1800 & 3.33 & 200 & 10 & 100 & 10 \\
\hline G1-T2.5-A4.0 & 600 & 2.5 & 236 & 2400 & 4.44 & 200 & 10 & 100 & 10 \\
\hline G1-T3.0-A0.5 & 600 & 3.0 & 197 & 300 & 0.56 & 200 & 10 & 100 & 10 \\
\hline G1-T3.0-A1.0 & 600 & 3.0 & 197 & 600 & 1.11 & 200 & 10 & 100 & 10 \\
\hline G1-T3.0-A2.0 & 600 & 3.0 & 197 & 1200 & 2.22 & 200 & 10 & 100 & 10 \\
\hline G1-T3.0-A3.0 & 600 & 3.0 & 197 & 1800 & 3.33 & 200 & 10 & 100 & 10 \\
\hline G1-T3.0-A4.0 & 600 & 3.0 & 197 & 2400 & 4.44 & 200 & 10 & 100 & 10 \\
\hline G1-T4.0-A0.5 & 600 & 4.0 & 148 & 300 & 0.56 & 200 & 10 & 100 & 10 \\
\hline G1-T4.0-A1.0 & 600 & 4.0 & 148 & 600 & 1.11 & 200 & 10 & 100 & 10 \\
\hline G1-T4.0-A2.0 & 600 & 4.0 & 148 & 1200 & 2.22 & 200 & 10 & 100 & 10 \\
\hline G1-T4.0-A3.0 & 600 & 4.0 & 148 & 1800 & 3.33 & 200 & 10 & 100 & 10 \\
\hline G1-T4.0-A4.0 & 600 & 4.0 & 148 & 2400 & 4.44 & 200 & 10 & 100 & 10 \\
\hline G1-T6.0-A0.5 & 600 & 6.0 & 98 & 300 & 0.56 & 200 & 10 & 100 & 10 \\
\hline G1-T6.0-A1.0 & 600 & 6.0 & 98 & 600 & 1.11 & 200 & 10 & 100 & 10 \\
\hline G1-T6.0-A2.0 & 600 & 6.0 & 98 & 1200 & 2.22 & 200 & 10 & 100 & 10 \\
\hline G1-T6.0-A3.0 & 600 & 6.0 & 98 & 1800 & 3.33 & 200 & 10 & 100 & 10 \\
\hline G1-T6.0-A4.0 & 600 & 6.0 & 98 & 2400 & 4.44 & 200 & 10 & 100 & 10 \\
\hline G1-T12.0-A0.5 & 600 & 12.0 & 49 & 300 & 0.56 & 200 & 10 & 100 & 10 \\
\hline G1-T12.0-A1.0 & 600 & 12.0 & 49 & 600 & 1.11 & 200 & 10 & 100 & 10 \\
\hline G1-T12.0-A2.0 & 600 & 12.0 & 49 & 1200 & 2.22 & 200 & 10 & 100 & 10 \\
\hline G1-T12.0-A3.0 & 600 & 12.0 & 49 & 1800 & 3.33 & 200 & 10 & 100 & 10 \\
\hline G1-T12.0-A4.0 & 600 & 12.0 & 49 & 2400 & 4.44 & 200 & 10 & 100 & 10 \\
\hline
\end{tabular}


Table 4. Cross-section Dimensions of Parametric Study for Group 2

\begin{tabular}{|c|c|c|c|c|c|c|c|c|c|}
\hline \multirow{3}{*}{ Specimen } & \multicolumn{3}{|c|}{ Web } & \multicolumn{2}{|c|}{ Space } & \multicolumn{2}{|c|}{ Flange } & \multicolumn{2}{|c|}{ Stiffener } \\
\hline & $d_{c}$ & $t_{w}$ & $h_{w} / t_{w}$ & $a$ & $a / b_{w}$ & $b_{f}$ & $t_{f}$ & $b_{s}$ & $t_{s}$ \\
\hline & $(\mathrm{mm})$ & $(\mathrm{mm})$ & & $(\mathrm{mm})$ & & $(\mathrm{mm})$ & $(\mathrm{mm})$ & $(\mathrm{mm})$ & $(\mathrm{mm})$ \\
\hline G2-T1.5-F2-A1.0 & 600 & 1.5 & 398 & 600 & 1.10 & 200 & 3.0 & 100 & 10 \\
\hline G2-T1.5-F3-A1.0 & 600 & 1.5 & 397 & 600 & 1.10 & 200 & 4.5 & 100 & 10 \\
\hline G2-T1.5-F4-A1.0 & 600 & 1.5 & 396 & 600 & 1.10 & 200 & 6.0 & 100 & 10 \\
\hline G2-T1.5-F5-A1.0 & 600 & 1.5 & 395 & 600 & 1.11 & 200 & 7.5 & 100 & 10 \\
\hline G2-T2.0-F2-A1.0 & 600 & 2.0 & 298 & 600 & 1.10 & 200 & 4.0 & 100 & 10 \\
\hline G2-T2.0-F3-A1.0 & 600 & 2.0 & 297 & 600 & 1.10 & 200 & 6.0 & 100 & 10 \\
\hline G2-T2.0-F4-A1.0 & 600 & 2.0 & 296 & 600 & 1.11 & 200 & 8.0 & 100 & 10 \\
\hline G2-T2.0-F5-A1.0 & 600 & 2.0 & 295 & 600 & 1.11 & 200 & 10.0 & 100 & 10 \\
\hline G2-T2.5-F2-A1.0 & 600 & 2.5 & 238 & 600 & 1.10 & 200 & 5.0 & 100 & 10 \\
\hline G2-T2.5-F3-A1.0 & 600 & 2.5 & 237 & 600 & 1.11 & 200 & 7.5 & 100 & 10 \\
\hline G2-T2.5-F4-A1.0 & 600 & 2.5 & 236 & 600 & 1.11 & 200 & 10.0 & 100 & 10 \\
\hline G2-T2.5-F5-A1.0 & 600 & 2.5 & 235 & 600 & 1.12 & 200 & 12.5 & 100 & 10 \\
\hline G2-T3.0-F2-A1.0 & 600 & 3.0 & 198 & 600 & 1.10 & 200 & 6.0 & 100 & 10 \\
\hline G2-T3.0-F3-A1.0 & 600 & 3.0 & 197 & 600 & 1.11 & 200 & 9.0 & 100 & 10 \\
\hline G2-T3.0-F4-A1.0 & 600 & 3.0 & 196 & 600 & 1.12 & 200 & 12.0 & 100 & 10 \\
\hline G2-T3.0-F5-A1.0 & 600 & 3.0 & 195 & 600 & 1.12 & 200 & 15.0 & 100 & 10 \\
\hline G2-T6.0-F2-A1.0 & 600 & 6.0 & 98 & 600 & 1.12 & 200 & 12.0 & 100 & 10 \\
\hline G2-T6.0-F3-A1.0 & 600 & 6.0 & 97 & 600 & 1.13 & 200 & 18.0 & 100 & 10 \\
\hline G2-T6.0-F4-A1.0 & 600 & 6.0 & 96 & 600 & 1.14 & 200 & 24.0 & 100 & 10 \\
\hline G2-T6.0-F5-A1.0 & 600 & 6.0 & 95 & 600 & 1.15 & 200 & 30.0 & 100 & 10 \\
\hline G2-T1.5-F2-A2.0 & 600 & 1.5 & 398 & 1200 & 2.19 & 200 & 3.0 & 100 & 10 \\
\hline G2-T1.5-F3-A2.0 & 600 & 1.5 & 397 & 1200 & 2.20 & 200 & 4.5 & 100 & 10 \\
\hline G2-T1.5-F4-A2.0 & 600 & 1.5 & 396 & 1200 & 2.21 & 200 & 6.0 & 100 & 10 \\
\hline G2-T1.5-F5-A2.0 & 600 & 1.5 & 395 & 1200 & 2.21 & 200 & 7.5 & 100 & 10 \\
\hline G2-T2.0-F2-A2.0 & 600 & 2.0 & 298 & 1200 & 2.20 & 200 & 4.0 & 100 & 10 \\
\hline G2-T2.0-F3-A2.0 & 600 & 2.0 & 297 & 1200 & 2.21 & 200 & 6.0 & 100 & 10 \\
\hline G2-T2.0-F4-A2.0 & 600 & 2.0 & 296 & 1200 & 2.21 & 200 & 8.0 & 100 & 10 \\
\hline G2-T2.0-F5-A2.0 & 600 & 2.0 & 295 & 1200 & 2.22 & 200 & 10.0 & 100 & 10 \\
\hline G2-T2.5-F2-A2.0 & 600 & 2.5 & 238 & 1200 & 2.20 & 200 & 5.0 & 100 & 10 \\
\hline G2-T2.5-F3-A2.0 & 600 & 2.5 & 237 & 1200 & 2.21 & 200 & 7.5 & 100 & 10 \\
\hline G2-T2.5-F4-A2.0 & 600 & 2.5 & 236 & 1200 & 2.22 & 200 & 10.0 & 100 & 10 \\
\hline G2-T2.5-F5-A2.0 & 600 & 2.5 & 235 & 1200 & 2.23 & 200 & 12.5 & 100 & 10 \\
\hline G2-T3.0-F2-A2.0 & 600 & 3.0 & 198 & 1200 & 2.21 & 200 & 6.0 & 100 & 10 \\
\hline G2-T3.0-F3-A2.0 & 600 & 3.0 & 197 & 1200 & 2.22 & 200 & 9.0 & 100 & 10 \\
\hline G2-T3.0-F4-A2.0 & 600 & 3.0 & 196 & 1200 & 2.23 & 200 & 12.0 & 100 & 10 \\
\hline G2-T3.0-F5-A2.0 & 600 & 3.0 & 195 & 1200 & 2.24 & 200 & 15.0 & 100 & 10 \\
\hline G2-T6.0-F2-A2.0 & 600 & 6.0 & 98 & 1200 & 2.23 & 200 & 12.0 & 100 & 10 \\
\hline G2-T6.0-F3-A2.0 & 600 & 6.0 & 97 & 1200 & 2.26 & 200 & 18.0 & 100 & 10 \\
\hline G2-T6.0-F4-A2.0 & 600 & 6.0 & 96 & 1200 & 2.28 & 200 & 24.0 & 100 & 10 \\
\hline G2-T6.0-F5-A2.0 & 600 & 6.0 & 95 & 1200 & 2.31 & 200 & 30.0 & 100 & 10 \\
\hline
\end{tabular}


Table 5. Cross-section Dimensions of Parametric Study for Group 3

\begin{tabular}{|c|c|c|c|c|c|c|c|c|c|}
\hline \multirow{3}{*}{ Specimen } & \multicolumn{3}{|c|}{ Web } & \multicolumn{2}{|c|}{ Space } & \multicolumn{2}{|c|}{ Flange } & \multicolumn{2}{|c|}{ Stiffener } \\
\hline & $d_{c}$ & $t_{w}$ & $h_{w} / t_{w}$ & $a$ & $a / b_{w}$ & $b_{f}$ & $t_{f}$ & $b_{s}$ & $t_{s}$ \\
\hline & $(\mathrm{mm})$ & $(\mathrm{mm})$ & & $(\mathrm{mm})$ & & $(\mathrm{mm})$ & $(\mathrm{mm})$ & $(\mathrm{mm})$ & $(\mathrm{mm})$ \\
\hline G3-T2.0-S2-A0.5 & 600 & 2.0 & 295 & 300 & 0.56 & 200 & 10 & 100 & 4.0 \\
\hline G3-T2.0-S3-A0.5 & 600 & 2.0 & 295 & 300 & 0.56 & 200 & 10 & 100 & 6.0 \\
\hline G3-T2.0-S4-A0.5 & 600 & 2.0 & 295 & 300 & 0.56 & 200 & 10 & 100 & 8.0 \\
\hline G3-T2.0-S5-A0.5 & 600 & 2.0 & 295 & 300 & 0.56 & 200 & 10 & 100 & 10.0 \\
\hline G3-T2.5-S2-A0.5 & 600 & 2.5 & 236 & 300 & 0.56 & 200 & 10 & 100 & 5.0 \\
\hline G3-T2.5-S3-A0.5 & 600 & 2.5 & 236 & 300 & 0.56 & 200 & 10 & 100 & 7.5 \\
\hline G3-T2.5-S4-A0.5 & 600 & 2.5 & 236 & 300 & 0.56 & 200 & 10 & 100 & 10.0 \\
\hline G3-T2.5-S5-A0.5 & 600 & 2.5 & 236 & 300 & 0.56 & 200 & 10 & 100 & 12.5 \\
\hline G3-T3.0-S2-A0.5 & 600 & 3.0 & 197 & 300 & 0.56 & 200 & 10 & 100 & 6.0 \\
\hline G3-T3.0-S3-A0.5 & 600 & 3.0 & 197 & 300 & 0.56 & 200 & 10 & 100 & 9.0 \\
\hline G3-T3.0-S4-A0.5 & 600 & 3.0 & 197 & 300 & 0.56 & 200 & 10 & 100 & 12.0 \\
\hline G3-T3.0-S5-A0.5 & 600 & 3.0 & 197 & 300 & 0.56 & 200 & 10 & 100 & 15.0 \\
\hline G3-T6.0-S2-A0.5 & 600 & 6.0 & 98 & 300 & 0.56 & 200 & 10 & 100 & 12.0 \\
\hline G3-T6.0-S3-A0.5 & 600 & 6.0 & 98 & 300 & 0.56 & 200 & 10 & 100 & 18.0 \\
\hline G3-T6.0-S4-A0.5 & 600 & 6.0 & 98 & 300 & 0.56 & 200 & 10 & 100 & 24.0 \\
\hline G3-T6.0-S5-A0.5 & 600 & 6.0 & 98 & 300 & 0.56 & 200 & 10 & 100 & 30.0 \\
\hline G3-T1.5-S2-A1.0 & 600 & 1.5 & 393 & 600 & 1.11 & 200 & 10 & 100 & 3.0 \\
\hline G3-T1.5-S3-A1.0 & 600 & 1.5 & 393 & 600 & 1.11 & 200 & 10 & 100 & 4.5 \\
\hline G3-T1.5-S4-A1.0 & 600 & 1.5 & 393 & 600 & 1.11 & 200 & 10 & 100 & 6.0 \\
\hline G3-T1.5-S5-A1.0 & 600 & 1.5 & 393 & 600 & 1.11 & 200 & 10 & 100 & 7.5 \\
\hline G3-T2.0-S2-A1.0 & 600 & 2.0 & 295 & 600 & 1.11 & 200 & 10 & 100 & 4.0 \\
\hline G3-T2.0-S3-A1.0 & 600 & 2.0 & 295 & 600 & 1.11 & 200 & 10 & 100 & 6.0 \\
\hline G3-T2.0-S4-A1.0 & 600 & 2.0 & 295 & 600 & 1.11 & 200 & 10 & 100 & 8.0 \\
\hline G3-T2.0-S5-A1.0 & 600 & 2.0 & 295 & 600 & 1.11 & 200 & 10 & 100 & 10.0 \\
\hline G3-T2.5-S2-A1.0 & 600 & 2.5 & 236 & 600 & 1.11 & 200 & 10 & 100 & 5.0 \\
\hline G3-T2.5-S3-A1.0 & 600 & 2.5 & 236 & 600 & 1.11 & 200 & 10 & 100 & 7.5 \\
\hline G3-T2.5-S4-A1.0 & 600 & 2.5 & 236 & 600 & 1.11 & 200 & 10 & 100 & 10.0 \\
\hline G3-T2.5-S5-A1.0 & 600 & 2.5 & 236 & 600 & 1.11 & 200 & 10 & 100 & 12.5 \\
\hline G3-T3.0-S2-A1.0 & 600 & 3.0 & 197 & 600 & 1.11 & 200 & 10 & 100 & 6.0 \\
\hline G3-T3.0-S3-A1.0 & 600 & 3.0 & 197 & 600 & 1.11 & 200 & 10 & 100 & 9.0 \\
\hline G3-T3.0-S4-A 1.0 & 600 & 3.0 & 197 & 600 & 1.11 & 200 & 10 & 100 & 12.0 \\
\hline G3-T3.0-S5-A1.0 & 600 & 3.0 & 197 & 600 & 1.11 & 200 & 10 & 100 & 15.0 \\
\hline G3-T6.0-S2-A1.0 & 600 & 6.0 & 98 & 600 & 1.11 & 200 & 10 & 100 & 12.0 \\
\hline G3-T6.0-S3-A1.0 & 600 & 6.0 & 98 & 600 & 1.11 & 200 & 10 & 100 & 18.0 \\
\hline G3-T6.0-S4-A1.0 & 600 & 6.0 & 98 & 600 & 1.11 & 200 & 10 & 100 & 24.0 \\
\hline G3-T6.0-S5-A1.0 & 600 & 6.0 & 98 & 600 & 1.11 & 200 & 10 & 100 & 30.0 \\
\hline
\end{tabular}


Table 6. Cross-section Dimensions of Parametric Study for Group 4

\begin{tabular}{l|c|c|c|c|c|c|c|c|c}
\hline \hline \multirow{3}{*}{ Specimen } & \multicolumn{3}{c|}{ Web } & \multicolumn{2}{c|}{ Space } & \multicolumn{2}{c|}{ Flange } & \multicolumn{2}{c}{ Stiffener } \\
\cline { 2 - 11 } & $d_{c}$ & $t_{w}$ & $h_{w} / t_{w}$ & $a$ & $a / b_{w}$ & $b_{f}$ & $t_{f}$ & $b_{s}$ & $t_{s}$ \\
\cline { 2 - 10 } & $(\mathrm{mm})$ & $(\mathrm{mm})$ & & $(\mathrm{mm})$ & & $(\mathrm{mm})$ & $(\mathrm{mm})$ & $(\mathrm{mm})$ & $(\mathrm{mm})$ \\
\hline G4-T1.5 & 600 & 1.5 & 393 & 600 & 1.11 & 200 & 10 & 50 & 10 \\
G4-T2.0 & 600 & 2.0 & 295 & 600 & 1.11 & 200 & 10 & 50 & 10 \\
G4-T2.5 & 600 & 2.5 & 236 & 600 & 1.11 & 200 & 10 & 50 & 10 \\
G4-T3.0 & 600 & 3.0 & 197 & 600 & 1.11 & 200 & 10 & 50 & 10 \\
G4-T4.0 & 600 & 4.0 & 148 & 600 & 1.11 & 200 & 10 & 50 & 10 \\
G4-T6.0 & 600 & 6.0 & 98 & 600 & 1.11 & 200 & 10 & 50 & 10 \\
G4-T12.0 & 600 & 12.0 & 49 & 600 & 1.11 & 200 & 10 & 50 & 10 \\
\hline \hline
\end{tabular}

\section{DISCUSSION}

The web slenderness $\left(h_{w} / t_{w}\right)$ has significant effect on the shear resistance of aluminum alloy plate girder, as shown in Figure 5, where the vertical axis of the graph shows the normalized shear resistance ( $\left.\rho=V /\left(t_{w} h_{w} f_{w} / \sqrt{3}\right)\right)$ and the horizontal axis of the graph shows the web slenderness $\left(h_{w} / t_{w}\right)$. Five different aspect ratios $\left(a / b_{w}\right)$ of $0.56,1.11,2.22,3.33$ and 4.44 are considered. It is shown that the normalized shear resistance decreases as the web slenderness increases.

It is known that when the web is in the post-buckling range, a load-carrying mechanism is developed, whereby any additional shear load is carried by an inclined tensile membrane stress field. This tensile field anchors against the top and bottom flanges and against the transverse stiffener on either side of the web panel. Hence, the effects of the bending rigidity of the flanges and the non-rigid end post are also investigated in this study. Figures 6 and 7 show the effect of the bending rigidity of the flanges on the shear resistance of aluminum alloy plate girders for the case of the aspect ratios $a / b_{w}=1.11$ and 2.22 , respectively. It is shown that the bending rigidity of the flanges has significant effect on the shear resistance of aluminum alloy plate girder.

In order to study the effect of the non-rigid end post, the shear resistances of some aluminum alloy plate girders with different dimensions of non-rigid end post were calculated. Figures 8 and 9 show the effect of the non-rigid end post on the shear resistance of aluminum alloy plate girders for the case of the aspect ratios $a / b_{w}=0.56$ and 1.11, respectively. The ratio of shear resistance of aluminum plate girders with half width of stiffeners to that of aluminum alloy plate girders with full width of stiffeners $(V(0.5 b s) / V(b s))$ against the web slenderness $\left(h_{w} / t_{w}\right)$ is plotted in Figure 10. It is shown that the non-rigid end post has significant effect on the shear resistance of aluminum alloy plate girder. 


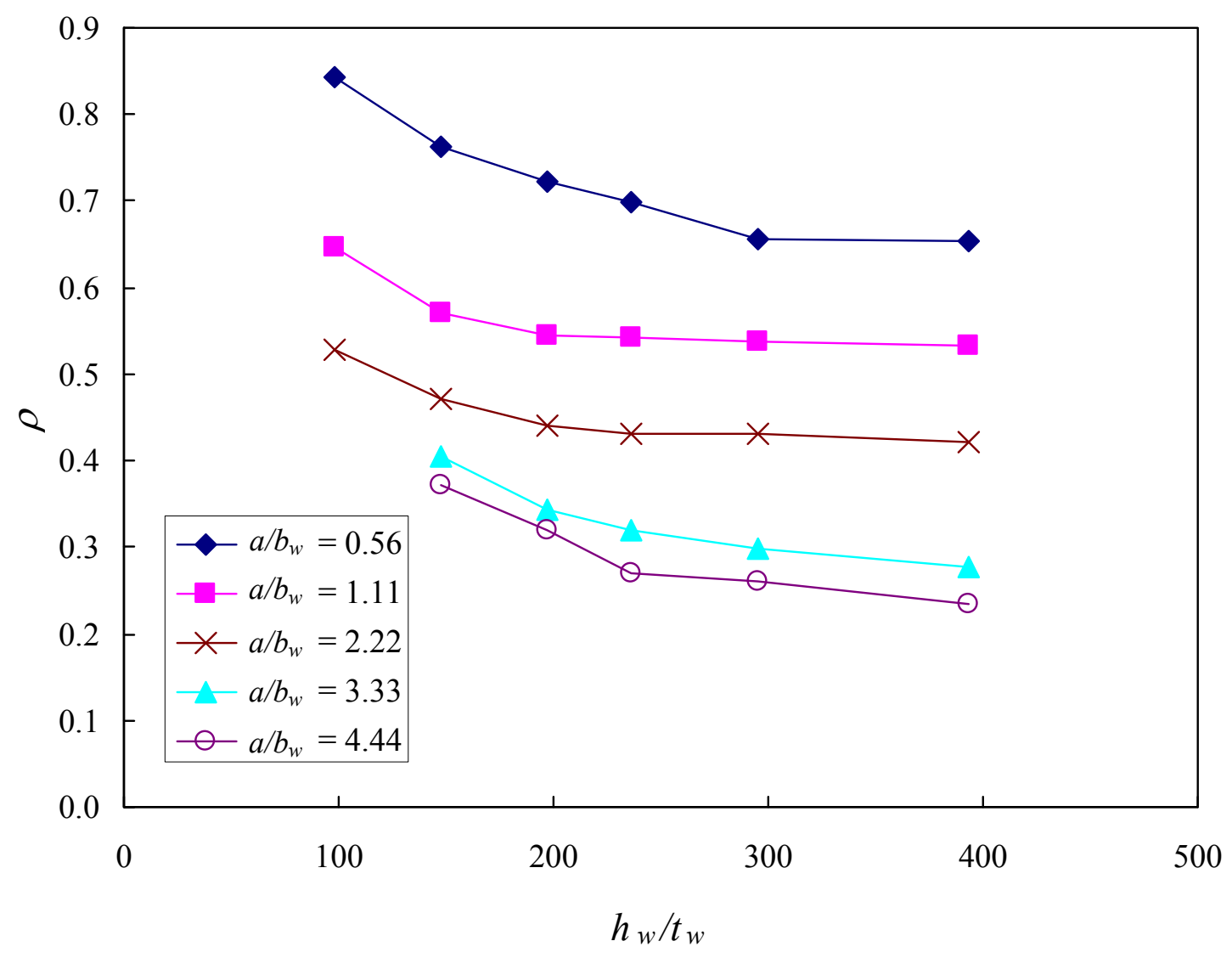

Figure 5. The Effect of Web Slenderness

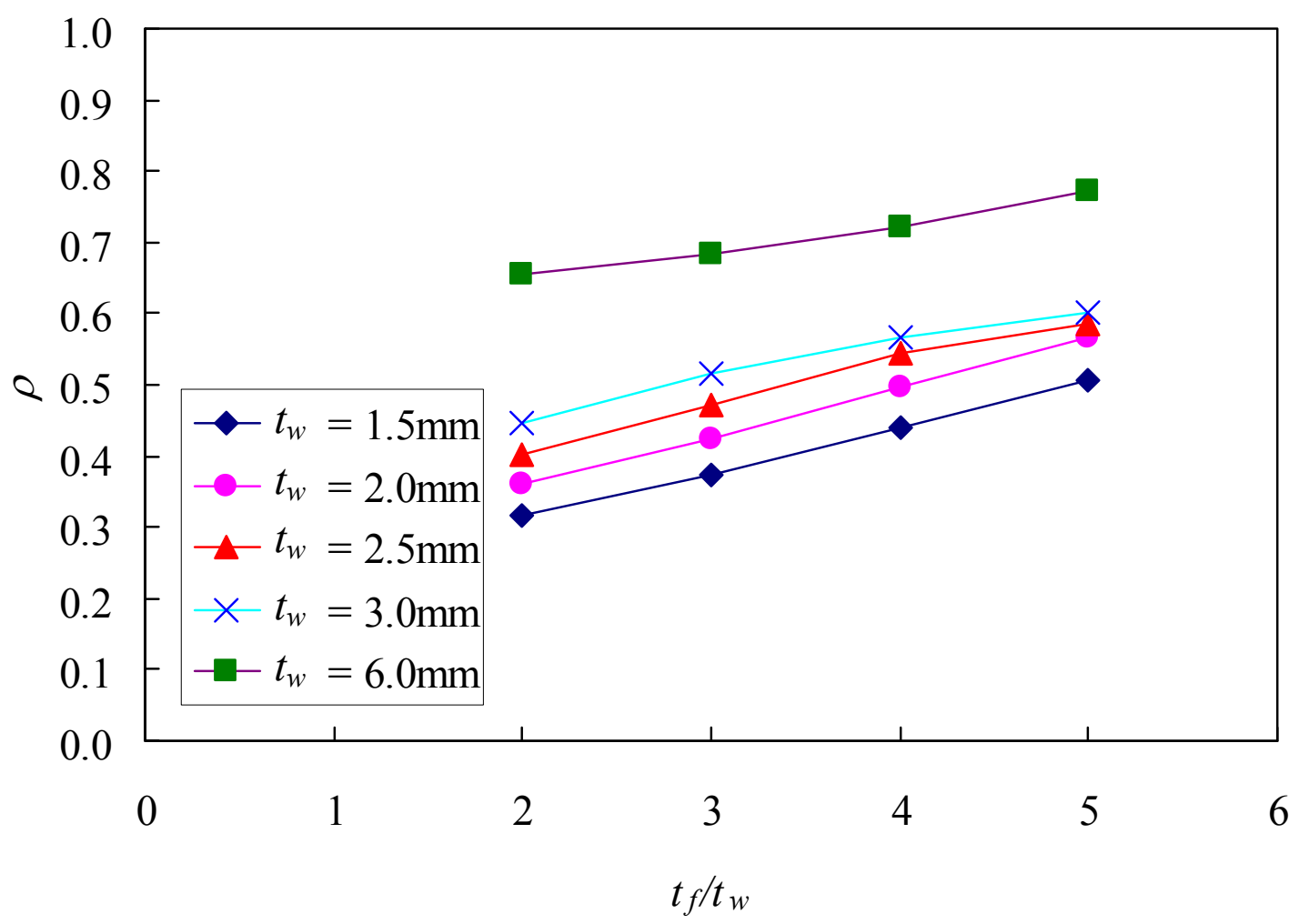

Figure 6. The Effect of Bending Rigidity of the Flange (Aspect Ratio $a / b_{w}=1.11$ ) 


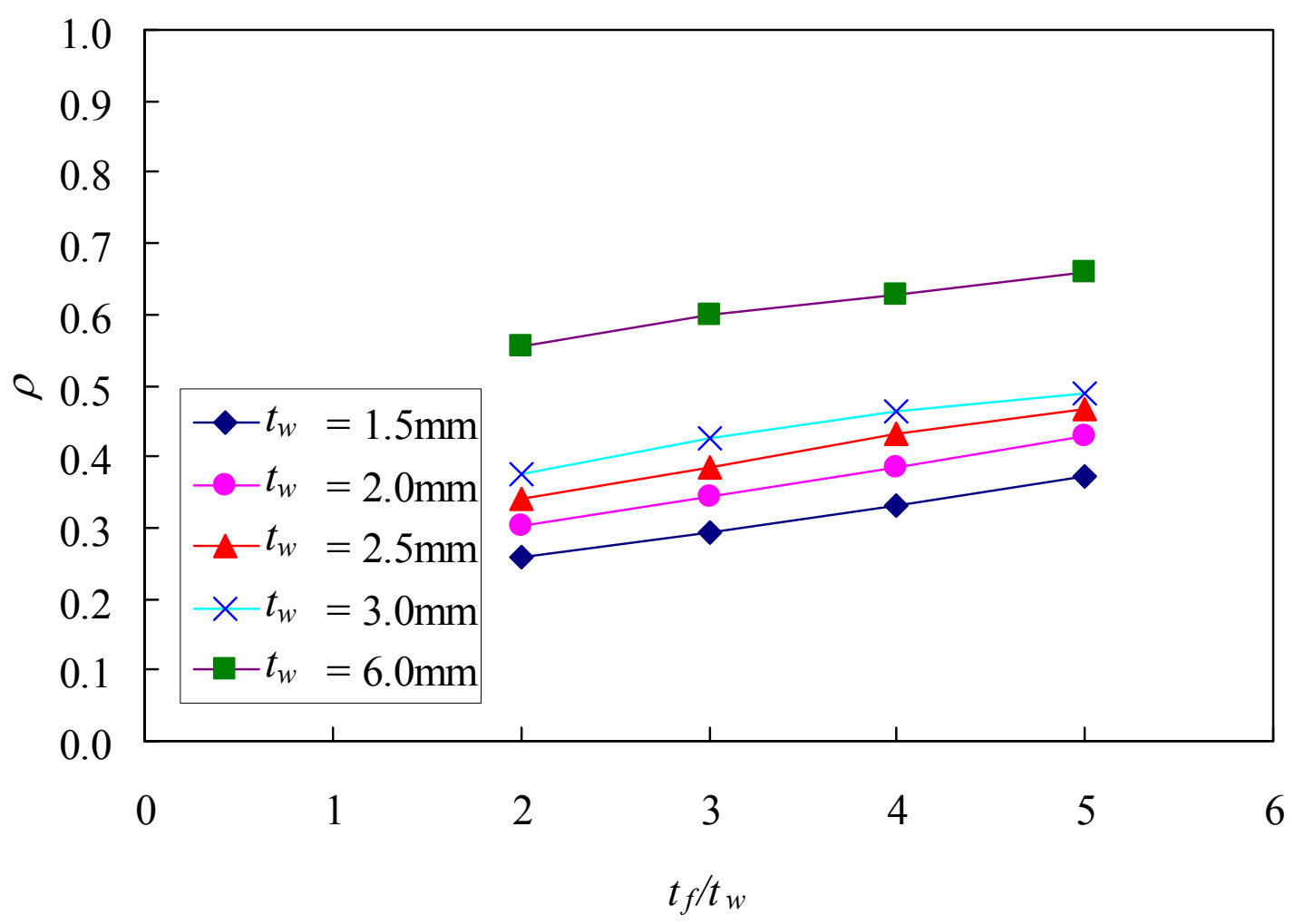

Figure 7. The Effect of Bending Rigidity of the Flange (Aspect Ratio $a / b_{w}=2.22$ )

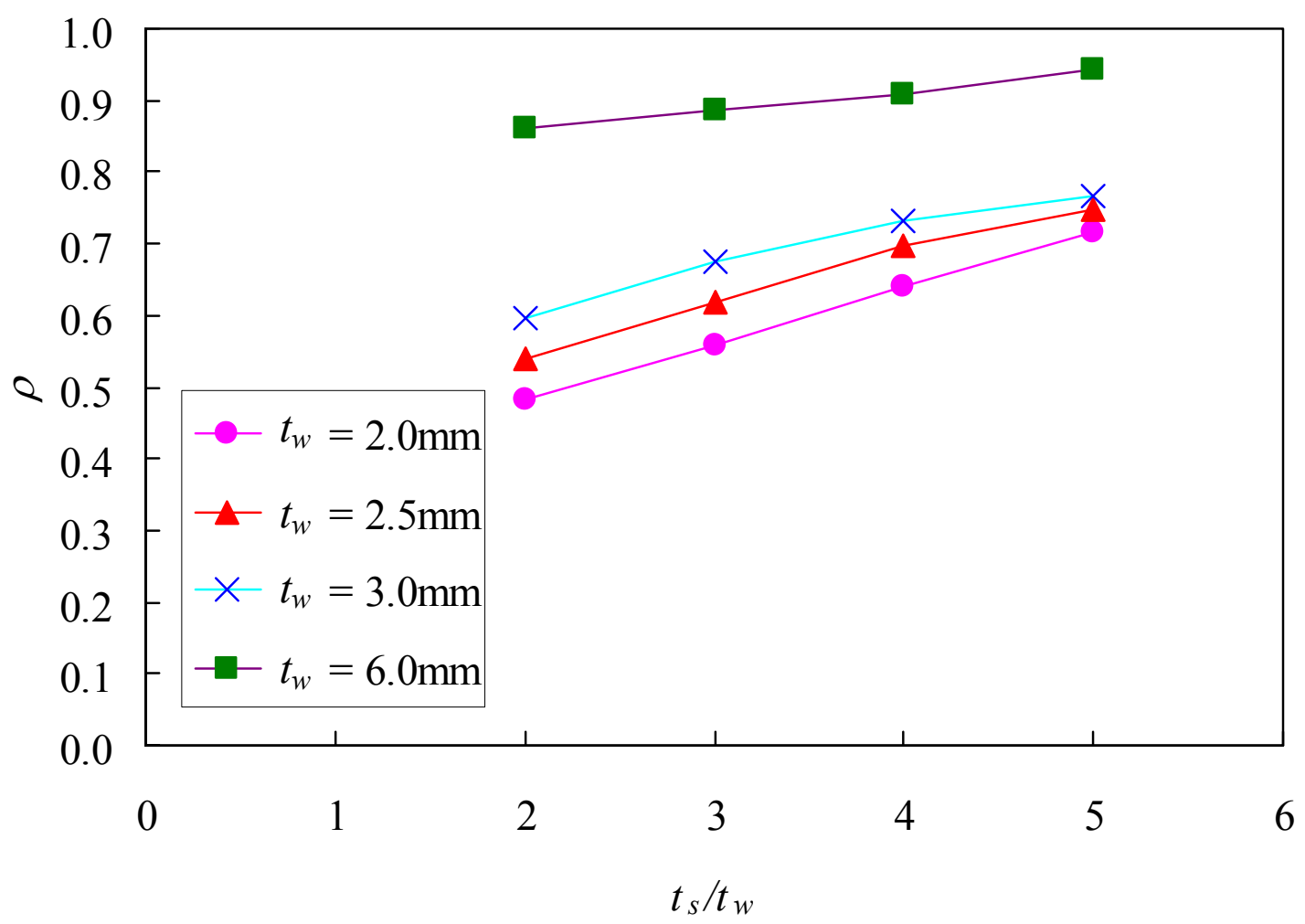

Figure 8. The Effect of Non-rigid End Post (Aspect Ratio $a / b_{w}=0.56$ ) 


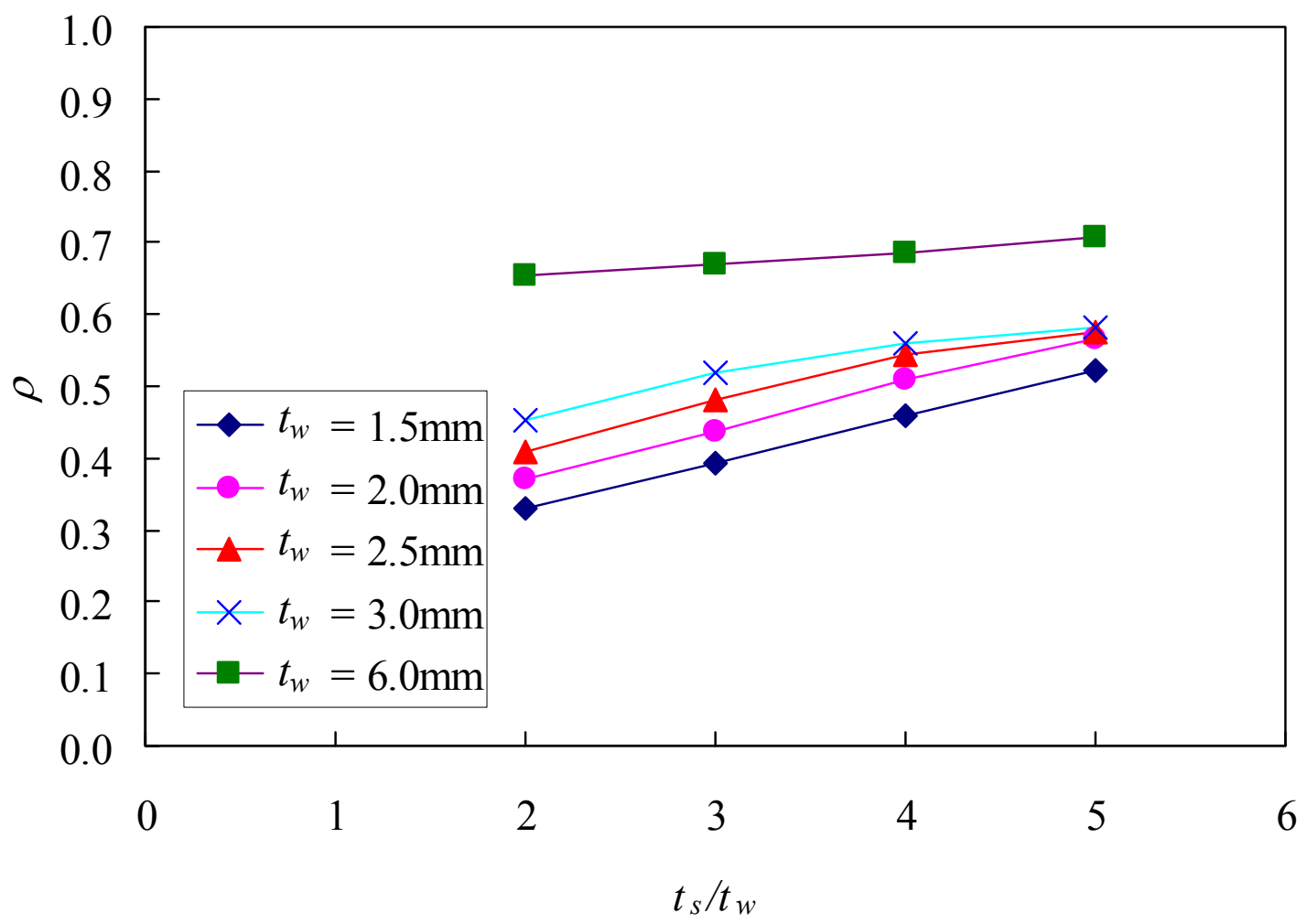

Figure 9. The Effect of Non-rigid End Post (Aspect Ratio $a / b_{w}=1.11$ )

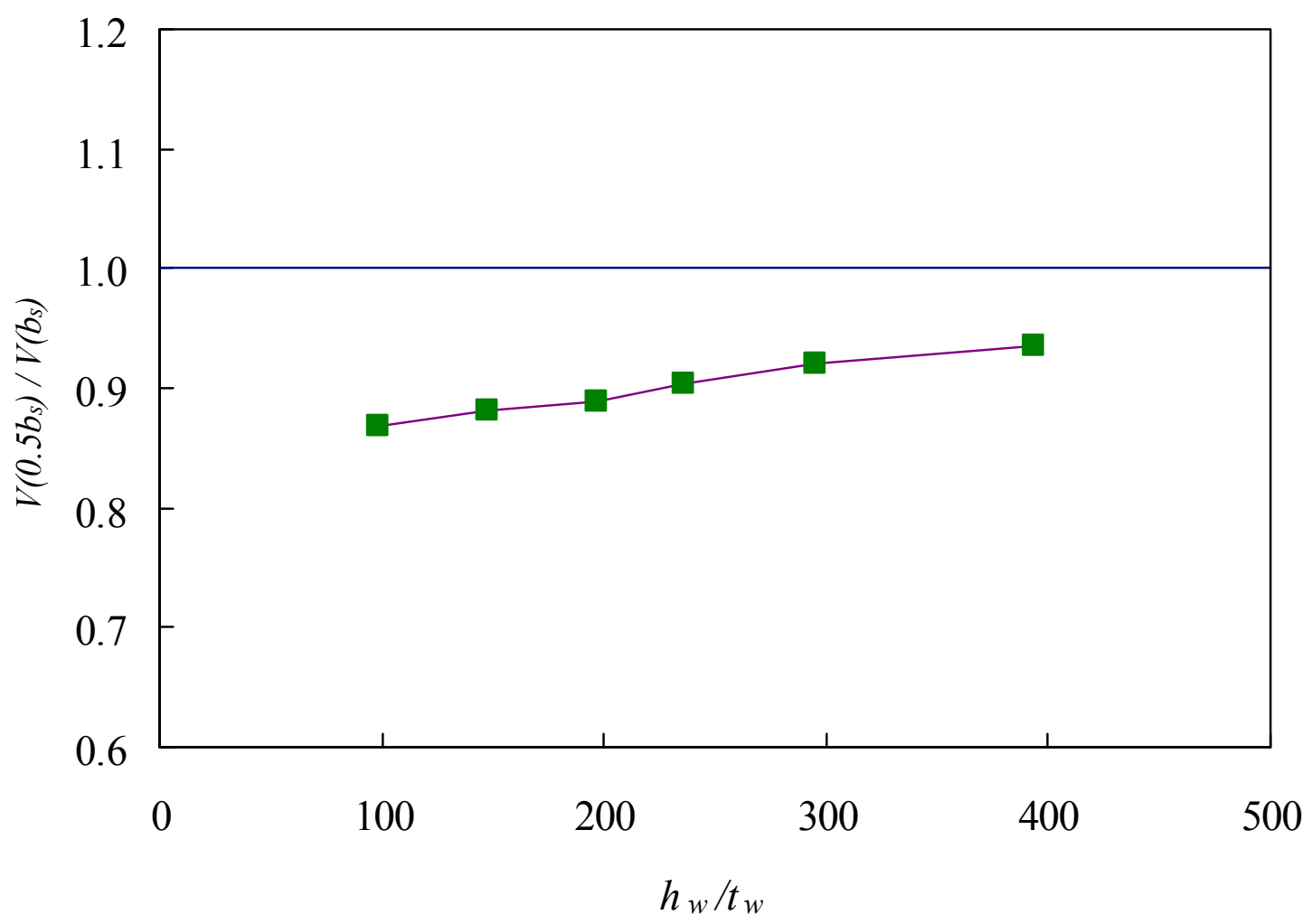

Figure 10. Comparison of Shear Strengths with Different Widths of Non-rigid End Post (Aspect Ratio $a / b_{w}=1.11$ ) 


\section{DESIGN RULES}

The current EC9 Code [12] and AA Specification [13] are used to predict the shear resistance of aluminum alloy plate girders. It should be noted that the end posts consisting of a single plate is belonged to the non-rigid end post. In EC9 Code, the shear design resistance $V_{E C}$ of aluminum alloy plate girder with web stiffeners is the sum of the contribution $V_{w, E C}$ of the web and $V_{f, E C}$ of the flanges.

$V_{E C}=V_{w, E C}+V_{f, E C}$

where $V_{w, E C}$ includes partial tension field action in the web according to Eqs. $2-5$ and $V_{f, E C}$ is an increase of the tension field caused by local bending resistance of the flanges according to Eqs. 6 7.

$V_{w, E C}=\rho_{v} t_{w} h_{w} \frac{f_{w}}{\sqrt{3}}$

where $\rho_{v}$ is a factor for shear buckling obtained from the Table $7, t_{w}$ is the web thickness, $h_{w}$ is the web depth between flanges and $f_{w}$ is the tensile yield stress of the web material. The slenderness parameter $\lambda_{\mathrm{w}}$ is defined as:

$\lambda_{w}=\frac{0.81}{\sqrt{k_{\tau}}} \frac{b_{w}}{t_{w}} \sqrt{\frac{f_{w}}{E}}$

where

$k_{\tau}=5.34+4.00\left(b_{w} / a\right)^{2} \quad$ when $a / b_{w} \geq 1$

$k_{\tau}=4.00+5.34\left(b_{w} / a\right)^{2} \quad$ when $a / b_{w}<1$

in which, $b_{w}$ is the depth of straight portion of a web excluding the welds, $a$ is the distance between transverse stiffeners and $E$ is the Young's modulus of the aluminum alloy material.

If the flange resistance is not completely utilized in withstanding the bending moment, then the shear resistance contribution $V_{f, \mathrm{EC}}$ from the flanges may be included in the shear buckling resistance as follows:

$V_{f, E C}=\frac{b_{f} t_{f}^{2} f_{f}}{c}\left(1-\left(\frac{M_{E d}}{M_{f, B S}}\right)^{2}\right)$

where $b_{f}$ is the flange width, $t_{f}$ is the flange thickness, $f_{f}$ is the yield stress of the flange material, $M_{E d}$ is the design bending moment and $M_{f, B S}$ is the design moment resistance of a cross-section considering the flanges only.

$c=a\left(0.08+\frac{4.4 b_{f} t_{f}^{2} f_{f}}{t_{w} b_{w}^{2} f_{w}}\right)$ 
In AA Specification, the shear design stress $\left(f_{v, A A}\right)$ of stiffened flat elements supported on both edges is defined as follows:

$$
\begin{array}{ll}
f_{v, A A}=f_{w} / \sqrt{3} & \text { for } a_{e} / t_{w} \leq \mathrm{S}_{1} \\
f_{v, A A}=1.375\left[B_{s}-1.25 D_{s} \frac{a_{e}}{t}\right] & \text { for } \mathrm{S}_{1}<a_{e} / t_{w} \leq \mathrm{S}_{2} \\
f_{v, A A}=\frac{1.375 \pi^{2} E}{\left(1.25 a_{e} / t\right)^{2}} & \text { for } \mathrm{S}_{2}<a_{e} / t_{w}
\end{array}
$$

where, $a_{e}=\frac{a_{1}}{\sqrt{1+0.7\left(a_{1} / a_{2}\right)^{2}}}, a_{1}$ is shorter dimension of rectangular panel, $a_{2}$ is longer dimension of rectangular panel, $S_{1}=\frac{B_{s}-\frac{f_{w}}{1.375 \sqrt{3}}}{1.25 D_{s}}$ and $\mathrm{S}_{2}=a_{e} / t_{w}$ at the intersection of Eqs. 9 and 10. The term $B_{s}$ and $D_{s}$ are defined in the AA Specification as:

$$
\begin{aligned}
& B_{s}=\frac{f_{w}}{\sqrt{3}}\left[1+\frac{\left(f_{w} / \sqrt{3}\right)^{1 / 3}}{17.7}\right] \\
& D_{s}=\frac{B_{s}}{10}\left(\frac{B_{s}}{E}\right)^{1 / 2}
\end{aligned}
$$

Table 7. Factor $\rho_{\mathrm{v}}$ for Shear Buckling

\begin{tabular}{cc|cc}
\hline \multicolumn{2}{c|}{ BS EN 1999-1-1 } & \multicolumn{2}{c}{ Proposed } \\
\hline Range of $\lambda_{\mathrm{w}}$ & Non-rigid end post & Range of $\lambda_{\mathrm{w}}$ & Non-rigid end post \\
$\lambda_{\mathrm{w}} \leq 0.83 / \eta$ & $\eta$ & $\lambda_{\mathrm{w}} \leq 0.83 / \eta$ & $\eta$ \\
$0.83 / \eta \leq \lambda_{\mathrm{w}}<0.937$ & $0.83 / \lambda_{\mathrm{w}}$ & $0.83 / \eta \leq \lambda_{\mathrm{w}}<2.3$ & $0.72 / \lambda_{\mathrm{w}}$ \\
$0.937 \leq \lambda_{\mathrm{w}}$ & $0.83 / \lambda_{\mathrm{w}}$ & $2.3 \leq \lambda_{\mathrm{w}}$ & $1.8 /\left(3.4+\lambda_{\mathrm{w}}\right)$ \\
\hline
\end{tabular}

$\eta=0.7+0.35 f_{\text {aw }} / f_{\text {ow }}$ but not more than 1.2 where $f_{\text {aw }}$ is the ultimate strength of the web material and $f_{\text {ow }}$ is the strength for overall yielding.

\section{RELIABILITY ANALYSIS}

The reliability of the design rules for aluminum alloy plate girders subject to shear force is evaluated using reliability analysis. The reliability index $(\beta)$ is a relative measure of the safety of the design. A target reliability index of 2.5 for aluminum alloy plate girders is recommended as a lower limit in the AA Specification [13]. The design rules are considered to be reliable if the reliability index is greater than 2.5. The resistance (capacity) factor $\left(\phi_{v l}\right)$ for shear resistance as 
recommended by the current EC9 Code [12] and AA Specification [13] are shown in Tables $8-11$. The load combinations of 1.35DL $+1.5 \mathrm{LL}$ and 1.2DL + 1.6LL as specified in the European Code and the American Society of Civil Engineers Standard [14], respectively, were used in the reliability analysis, where DL is the dead load and LL is the live load. The statistical parameters are obtained from the AA Specification for aluminum alloy plate girders subjected to shear force, where $M_{m}=1.10, F_{m}=1.00, V_{M}=0.06$, and $V_{F}=0.05$, which are the mean values and coefficients of variation for material properties and fabrication factors. The statistical parameters $U_{m}$ and $U_{P}$ are the mean value and coefficient of variation of load ratio, respectively, as shown in Tables $8-11$. In calculating the reliability index, the correction factor in the AA Specification was used. The respective resistance factor $\left(\phi_{v 1}\right)$ and load combinations for the current EC9 Code and AA Specification were used to calculate the corresponding reliability index $\left(\beta_{1}\right)$. For the purpose of direct comparison, a constant resistant factor $\left(\phi_{v 2}\right)$ of 0.8 and a load combination of 1.2DL $+1.6 \mathrm{LL}$ as specified in the AA Specification were used to calculate the reliability index $\left(\beta_{2}\right)$ for the EC9 Code and AA Specification, as shown in Tables $8-11$. Reliability analysis is detailed in the AA Specification [13].

\section{COMPARISON OF EXPERIMENTAL AND NUMERICAL RESULTS WITH CURRENT DESIGN STRENGTHS}

The shear ultimate loads $\left(V_{E x p}\right)$ obtained from the tests and the shear strengths $\left(V_{F E A}\right)$ predicted by the finite element analysis were compared with the nominal shear resistances predicted using the EC9 Code [12] and AA Specification [13]. Tables 8-11 show the comparison of the test results $\left(V_{E x p}\right)$ and the shear strengths $\left(V_{F E A}\right)$ predicted by the FEA with the unfactored design strengths. The design strengths were calculated using the measured cross-section dimensions of each specimen and the measured material properties.

The design strengths predicted by the EC9 Code are generally conservative but not reliable, except for Group 2 where the mean value of the load ratio $V / V_{E C}$ is 1.38 with the corresponding coefficient of variation (COV) of 0.181 and the reliability index $\beta_{1}=3.06$ and $\beta_{2}=3.62$, as shown in Table 9 . For AA Specification, the design strengths are generally very conservative. The maximum mean value of the load ratio $V / V_{A A}$ is 4.11 with the corresponding COV of 0.642 and the reliability indices $\left(\beta_{1}\right.$ and $\left.\beta_{2}\right)$ of 3.05 , as shown in Table 9 .

\section{MODIFIED DESIGN METHOD}

Modifications on the design rules of EC9 Code are made for the design of aluminum alloy plate girder with end posts consisting of a single plate. The only modification to the shear design resistance equation is the term related to the contribution $V_{w}$ of the web. The modified shear design resistance $V_{P}$ of aluminum alloy plate girder with web stiffeners is defined as:

$V_{P}=V_{w, P}+V_{f, P}$

where, $\quad V_{w, P}=\rho_{v} t_{w} h_{w} \frac{f_{w}}{\sqrt{3}}$ and the modified factor $\rho_{v}$ for shear buckling is shown in Table 7. The comparison of shear buckling factor $\rho_{v}$ predicted by the current EC9 Code and modified design method is shown in Figure 11. It should be noted that the contribution $V_{f, P}$ of the flanges remains the same and it is defined in Eqs $6-7$. The modified design method was calibrated against the experimental and numerical results. 
Table 8. Comparison of Experimental and Numerical Results with Design Strengths (Group 1)

\begin{tabular}{|c|c|c|c|c|c|c|c|c|c|}
\hline \multirow[b]{2}{*}{ Specimen } & \multicolumn{2}{|c|}{ Measured } & \multirow{2}{*}{$\begin{array}{c}\text { Test and } \\
\text { FEA } \\
V_{E x p} \text { and } \\
V_{F E A} \\
(\mathrm{kN})\end{array}$} & \multicolumn{3}{|c|}{ Design } & \multicolumn{3}{|c|}{ Comparison } \\
\hline & $h_{w} / t_{w}$ & $a / b_{w}$ & & $\begin{array}{c}V_{E C} \\
(\mathrm{kN})\end{array}$ & $\begin{array}{c}V_{A A} \\
(\mathrm{kN})\end{array}$ & $\begin{array}{c}V_{p} \\
(\mathrm{kN})\end{array}$ & $V / V_{E C}$ & $V / V_{A A}$ & $V / V_{p}$ \\
\hline Test I-7020 & 191 & 1.13 & 157.0 & 133.1 & 58.3 & 140.1 & 1.18 & 2.69 & 1.12 \\
\hline Test II-7020 & 190 & 1.14 & 118.5 & 134.5 & 58.3 & 141.4 & 0.88 & 2.03 & 0.84 \\
\hline Test III-7020 & 190 & 1.14 & 152.0 & 131.9 & 58.3 & 138.8 & 1.15 & 2.61 & 1.10 \\
\hline Test IV-7020 & 191 & 1.13 & 156.8 & 133.1 & 58.3 & 140.1 & 1.18 & 2.69 & 1.12 \\
\hline Test I-6082 & 190 & 1.13 & 119.0 & 112.1 & 59.5 & 111.4 & 1.06 & 2.00 & 1.07 \\
\hline Test II-6082 & 189 & 1.13 & 84.5 & 114.4 & 59.5 & 113.6 & 0.74 & 1.42 & 0.74 \\
\hline Test III-6082 & 189 & 1.13 & 113.5 & 112.6 & 59.6 & 111.8 & 1.01 & 1.90 & 1.02 \\
\hline Test IV-6082 & 190 & 1.13 & 134.5 & 110.4 & 59.3 & 109.8 & 1.22 & 2.27 & 1.22 \\
\hline G1-T1.5-A0.5 & 393 & 0.56 & 81.8 & 85.5 & 16.3 & 89.3 & 0.96 & 5.01 & 0.92 \\
\hline G1-T1.5-A1.0 & 393 & 1.11 & 66.8 & 46.2 & 6.5 & 52.8 & 1.45 & 10.28 & 1.27 \\
\hline G1-T1.5-A2.0 & 393 & 2.22 & 52.8 & 28.8 & 4.7 & 35.6 & 1.83 & 11.15 & 1.48 \\
\hline G1-T1.5-A3.0 & 393 & 3.33 & 34.8 & 23.6 & 4.4 & 30.5 & 1.47 & 7.89 & 1.14 \\
\hline G1-T1.5-A4.0 & 393 & 4.44 & 29.4 & 21.0 & 4.3 & 27.9 & 1.40 & 6.85 & 1.06 \\
\hline G1-T2.0-A0.5 & 295 & 0.56 & 109.4 & 119.3 & 38.7 & 118.3 & 0.92 & 2.82 & 0.92 \\
\hline G1-T2.0-A1.0 & 295 & 1.11 & 89.6 & 65.6 & 15.4 & 72.6 & 1.37 & 5.82 & 1.23 \\
\hline G1-T2.0-A2.0 & 295 & 2.22 & 71.9 & 42.7 & 11.2 & 51.0 & 1.68 & 6.41 & 1.41 \\
\hline G1-T2.0-A3.0 & 295 & 3.33 & 49.7 & 36.3 & 10.5 & 44.8 & 1.37 & 4.76 & 1.11 \\
\hline G1-T2.0-A4.0 & 295 & 4.44 & 43.7 & 32.9 & 10.2 & 41.5 & 1.33 & 4.29 & 1.05 \\
\hline G1-T2.5-A0.5 & 236 & 0.56 & 145.8 & 156.8 & 113.0 & 146.6 & 0.93 & 1.29 & 0.99 \\
\hline G1-T2.5-A1.0 & 236 & 1.11 & 113.3 & 87.5 & 30.1 & 92.7 & 1.29 & 3.77 & 1.22 \\
\hline $\mathrm{G} 1-\mathrm{T} 2.5-\mathrm{A} 2.0$ & 236 & 2.22 & 90.1 & 59.1 & 21.9 & 67.2 & 1.52 & 4.11 & 1.34 \\
\hline $\mathrm{G} 1-\mathrm{T} 2.5-\mathrm{A} 3.0$ & 236 & 3.33 & 66.8 & 51.3 & 20.4 & 59.9 & 1.30 & 3.27 & 1.12 \\
\hline G1-T2.5-A4.0 & 236 & 4.44 & 56.4 & 47.4 & 19.9 & 56.2 & 1.19 & 2.84 & 1.00 \\
\hline G1-T3.0-A0.5 & 197 & 0.56 & 180.9 & 198.6 & 187.3 & 183.9 & 0.91 & 0.97 & 0.98 \\
\hline G1-T3.0-A1.0 & 197 & 1.11 & 136.6 & 112.3 & 52.0 & 112.8 & 1.22 & 2.63 & 1.21 \\
\hline G1-T3.0-A2.0 & 197 & 2.22 & 110.4 & 77.8 & 37.9 & 83.6 & 1.42 & 2.91 & 1.32 \\
\hline G1-T3.0-A3.0 & 197 & 3.33 & 86.2 & 68.4 & 35.3 & 75.2 & 1.26 & 2.44 & 1.15 \\
\hline G1-T3.0-A4.0 & 197 & 4.44 & 79.8 & 63.2 & 34.4 & 70.3 & 1.26 & 2.32 & 1.13 \\
\hline G1-T4.0-A0.5 & 148 & 0.56 & 254.3 & 295.8 & 334.0 & 269.6 & 0.86 & 0.76 & 0.94 \\
\hline G1-T4.0-A1.0 & 148 & 1.11 & 190.7 & 170.1 & 184.5 & 153.5 & 1.12 & 1.03 & 1.24 \\
\hline G1-T4.0-A2.0 & 148 & 2.22 & 157.3 & 121.7 & 114.2 & 115.5 & 1.29 & 1.38 & 1.36 \\
\hline G1-T4.0-A3.0 & 148 & 3.33 & 134.9 & 107.9 & 96.7 & 104.0 & 1.25 & 1.39 & 1.30 \\
\hline G1-T4.0-A4.0 & 148 & 4.44 & 124.0 & 100.9 & 90.2 & 97.8 & 1.23 & 1.38 & 1.27 \\
\hline G1-T6.0-A0.5 & 98 & 0.56 & 422.7 & 547.0 & 500.9 & 488.0 & 0.77 & 0.84 & 0.87 \\
\hline G1-T6.0-A1.0 & 98 & 1.11 & 323.4 & 317.7 & 481.7 & 280.3 & 1.02 & 0.67 & 1.15 \\
\hline G1-T6.0-A2.0 & 98 & 2.22 & 265.1 & 239.0 & 411.4 & 207.4 & 1.11 & 0.64 & 1.28 \\
\hline G1-T6.0-A3.0 & 98 & 3.33 & $202.0^{*}$ & $\ldots$ & $\ldots$ & $\ldots$ & $\ldots$ & $\ldots$ & $\ldots$ \\
\hline G1-T6.0-A4.0 & 98 & 4.44 & $152.7^{*}$ & $\ldots$ & $\ldots$ & $\ldots$ & $\ldots$ & $\ldots$ & $\ldots$ \\
\hline G1-T12.0-A0.5 & 49 & 0.56 & $637.4^{*}$ & $\ldots$ & $\ldots$ & $\ldots$ & $\ldots$ & $\ldots$ & $\ldots$ \\
\hline G1-T12.0-A1.0 & 49 & 1.11 & $586.0^{*}$ & $\ldots$ & $\ldots$ & $\ldots$ & $\ldots$ & $\ldots$ & $\ldots$ \\
\hline G1-T12.0-A2.0 & 49 & 2.22 & $372.3^{*}$ & $\ldots$ & $\ldots$ & $\ldots$ & $\ldots$ & $\ldots$ & $\ldots$ \\
\hline G1-T12.0-A3.0 & 49 & 3.33 & $349.7 *$ & $\ldots$ & $\ldots$ & $\ldots$ & $\ldots$ & $\ldots$ & $\ldots$ \\
\hline \multirow[t]{7}{*}{ G1-T12.0-A4.0 } & 49 & 4.44 & $239.9^{*}$ & & & & & & \\
\hline & & & & \multicolumn{3}{|c|}{ Mean, $U_{m}$} & 1.20 & 3.26 & 1.13 \\
\hline & & & & \multicolumn{3}{|c|}{$\mathrm{COV}, U_{p}$} & 0.204 & 0.790 & 0.148 \\
\hline & & & & \multicolumn{3}{|c|}{ Reliability index, $\beta_{1}$} & 2.44 & 2.25 & 3.16 \\
\hline & & & & \multicolumn{3}{|c|}{ Resistance factor, $\phi_{v l}$} & 0.91 & 0.80 & 0.80 \\
\hline & & & & \multirow{2}{*}{\multicolumn{3}{|c|}{$\begin{array}{l}\text { Reliability index, } \beta_{2} \\
\text { Resistance factor, } \phi^{2}\end{array}$}} & 2.98 & 2.25 & 3.16 \\
\hline & & & & & & & 0.80 & 0.80 & 0.80 \\
\hline
\end{tabular}

Note: * Failed by bending, hence not compared with the shear design resistance. 
Table 9. Comparison of Numerical Results with Design Strengths (Group 2)

\begin{tabular}{|c|c|c|c|c|c|c|c|c|c|}
\hline \multirow[b]{2}{*}{ Specimen } & \multicolumn{2}{|c|}{ Measured } & $\begin{array}{l}\text { Test } \\
\text { and }\end{array}$ & \multicolumn{3}{|c|}{ Design } & \multicolumn{3}{|c|}{ Comparison } \\
\hline & $h_{w} / t_{w}$ & $a / b_{w}$ & $\begin{array}{c}V_{E x p} \text { and } \\
V_{F E A} \\
(\mathrm{kN})\end{array}$ & $\begin{array}{r}V_{E C} \\
(\mathrm{kN})\end{array}$ & $\begin{array}{r}V_{A A} \\
(\mathrm{kN})\end{array}$ & $\begin{array}{c}V_{p} \\
(\mathrm{kN})\end{array}$ & $V / V_{E C}$ & $V / V_{A A}$ & $V / V_{p}$ \\
\hline G2-T1.5-F2-A1.0 & 398 & 1.10 & 40.2 & 24.7 & 6.5 & 31.4 & 1.63 & 6.21 & 1.28 \\
\hline G2-T1.5-F3-A1.0 & 397 & 1.10 & 47.4 & 30.9 & 6.5 & 37.6 & 1.54 & 7.32 & 1.26 \\
\hline G2-T1.5-F4-A1.0 & 396 & 1.10 & 55.4 & 36.4 & 6.5 & 43.1 & 1.52 & 8.55 & 1.29 \\
\hline G2-T1.5-F5-A1.0 & 395 & 1.11 & 63.8 & 40.9 & 6.5 & 47.5 & 1.56 & 9.83 & 1.34 \\
\hline G2-T2.0-F2-A1.0 & 298 & 1.10 & 60.7 & 42.9 & 15.3 & 50.1 & 1.42 & 3.96 & 1.21 \\
\hline G2-T2.0-F3-A1.0 & 297 & 1.10 & 71.5 & 52.2 & 15.4 & 59.3 & 1.37 & 4.65 & 1.21 \\
\hline G2-T2.0-F4-A1.0 & 296 & 1.11 & 83.5 & 59.8 & 15.4 & 66.9 & 1.40 & 5.43 & 1.25 \\
\hline G2-T2.0-F5-A1.0 & 295 & 1.11 & 89.6 & 65.6 & 15.4 & 72.6 & 1.37 & 5.82 & 1.23 \\
\hline G2-T2.5-F2-A1.0 & 238 & 1.10 & 84.8 & 65.6 & 30.0 & 70.9 & 1.29 & 2.83 & 1.20 \\
\hline G2-T2.5-F3-A1.0 & 237 & 1.11 & 99.1 & 78.0 & 30.0 & 83.3 & 1.27 & 3.30 & 1.19 \\
\hline G2-T2.5-F4-A1.0 & 236 & 1.11 & 113.3 & 87.5 & 30.1 & 92.7 & 1.29 & 3.77 & 1.22 \\
\hline G2-T2.5-F5-A1.0 & 235 & 1.12 & 122.0 & 94.3 & 30.1 & 99.4 & 1.29 & 4.05 & 1.23 \\
\hline G2-T3.0-F2-A1.0 & 198 & 1.10 & 112.5 & 92.4 & 51.9 & 93.1 & 1.22 & 2.17 & 1.21 \\
\hline G2-T3.0-F3-A1.0 & 197 & 1.11 & 129.6 & 108.1 & 52.0 & 108.6 & 1.20 & 2.49 & 1.19 \\
\hline G2-T3.0-F4-A1.0 & 196 & 1.12 & 141.7 & 119.6 & 52.1 & 119.9 & 1.19 & 2.72 & 1.18 \\
\hline G2-T3.0-F5-A1.0 & 195 & 1.12 & 149.7 & 127.1 & 52.2 & 127.4 & 1.18 & 2.87 & 1.18 \\
\hline G2-T6.0-F2-A1.0 & 98 & 1.12 & 327.8 & 335.1 & 481.0 & 297.7 & 0.98 & 0.68 & 1.10 \\
\hline G2-T6.0-F3-A1.0 & 97 & 1.13 & 337.7 & 372.3 & 479.0 & 335.0 & 0.91 & 0.70 & 1.01 \\
\hline G2-T6.0-F4-A1.0 & 96 & 1.14 & 352.9 & 391.4 & 477.0 & 354.2 & 0.90 & 0.74 & 1.00 \\
\hline G2-T6.0-F5-A1.0 & 95 & 1.15 & 373.3 & 400.4 & 474.9 & 363.4 & 0.93 & 0.79 & 1.03 \\
\hline G2-T1.5-F2-A2.0 & 398 & 2.19 & 32.9 & 18.0 & 4.7 & 24.9 & 1.83 & 7.02 & 1.32 \\
\hline G2-T1.5-F3-A2.0 & 397 & 2.20 & 37.1 & 21.1 & 4.7 & 28.0 & 1.76 & 7.90 & 1.33 \\
\hline G2-T1.5-F4-A2.0 & 396 & 2.21 & 41.9 & 23.9 & 4.7 & 30.7 & 1.76 & 8.90 & 1.36 \\
\hline G2-T1.5-F5-A2.0 & 395 & 2.21 & 46.9 & 26.1 & 4.7 & 33.0 & 1.80 & 9.94 & 1.42 \\
\hline G2-T2.0-F2-A2.0 & 298 & 2.20 & 50.9 & 31.2 & 11.1 & 39.6 & 1.63 & 4.58 & 1.28 \\
\hline G2-T2.0-F3-A2.0 & 297 & 2.21 & 57.6 & 35.9 & 11.2 & 44.3 & 1.60 & 5.16 & 1.30 \\
\hline G2-T2.0-F4-A2.0 & 296 & 2.21 & 64.7 & 39.8 & 11.2 & 48.2 & 1.63 & 5.78 & 1.34 \\
\hline G2-T2.0-F5-A2.0 & 295 & 2.22 & 71.9 & 42.7 & 11.2 & 51.0 & 1.68 & 6.41 & 1.41 \\
\hline G2-T2.5-F2-A2.0 & 238 & 2.20 & 71.6 & 47.7 & 21.8 & 55.9 & 1.50 & 3.29 & 1.28 \\
\hline G2-T2.5-F3-A2.0 & 237 & 2.21 & 81.0 & 54.1 & 21.8 & 62.3 & 1.50 & 3.71 & 1.30 \\
\hline G2-T2.5-F4-A2.0 & 236 & 2.22 & 90.1 & 59.1 & 21.9 & 67.2 & 1.52 & 4.11 & 1.34 \\
\hline G2-T2.5-F5-A2.0 & 235 & 2.23 & 96.8 & 62.7 & 22.0 & 70.8 & 1.54 & 4.40 & 1.37 \\
\hline G2-T3.0-F2-A2.0 & 198 & 2.21 & 94.7 & 67.2 & 37.6 & 73.2 & 1.41 & 2.52 & 1.29 \\
\hline G2-T3.0-F3-A2.0 & 197 & 2.22 & 106.9 & 75.5 & 37.8 & 81.3 & 1.42 & 2.83 & 1.31 \\
\hline G2-T3.0-F4-A2.0 & 196 & 2.23 & 115.7 & 81.8 & 38.0 & 87.4 & 1.42 & 3.04 & 1.32 \\
\hline G2-T3.0-F5-A2.0 & 195 & 2.24 & 121.7 & 86.1 & 38.2 & 91.6 & 1.41 & 3.19 & 1.33 \\
\hline G2-T6.0-F2-A2.0 & 98 & 2.23 & 277.7 & 243.2 & 411.6 & 211.5 & 1.14 & 0.67 & 1.31 \\
\hline G2-T6.0-F3-A2.0 & 97 & 2.26 & 295.9 & 268.2 & 412.0 & 236.6 & 1.10 & 0.72 & 1.25 \\
\hline G2-T6.0-F4-A2.0 & 96 & 2.28 & 306.9 & 283.2 & 412.3 & 251.6 & 1.08 & 0.74 & 1.22 \\
\hline G2-T6.0-F5-A2.0 & 95 & 2.31 & 319.6 & 291.1 & 412.6 & 259.5 & 1.10 & 0.77 & 1.23 \\
\hline \multicolumn{7}{|c|}{ Mean, $U_{m}$} & 1.38 & 4.11 & 1.25 \\
\hline \multicolumn{7}{|c|}{$\operatorname{COV}, U_{p}$} & 0.181 & 0.642 & 0.078 \\
\hline \multicolumn{7}{|c|}{ Reliability index, $\beta_{1}$} & 3.06 & 3.05 & 4.05 \\
\hline \multicolumn{7}{|c|}{ Resistance factor, $\phi_{v l}$} & 0.91 & 0.80 & 0.80 \\
\hline \multicolumn{7}{|c|}{ Reliability index, $\beta_{2}$} & 3.62 & 3.05 & 4.05 \\
\hline & & & & \multicolumn{3}{|c|}{ Resistance factor, $\phi_{v 2}$} & 0.80 & 0.80 & 0.80 \\
\hline
\end{tabular}


Table 10. Comparison of Numerical Results with Design Strengths (Group 3)

\begin{tabular}{|c|c|c|c|c|c|c|c|c|c|}
\hline \multirow[b]{2}{*}{ Specimen } & \multicolumn{2}{|c|}{ Measured } & $\begin{array}{l}\text { Test } \\
\text { and } \\
\text { FEA }\end{array}$ & \multicolumn{3}{|c|}{ Design } & \multicolumn{3}{|c|}{ Comparison } \\
\hline & $h_{w} / t_{w}$ & $a / b_{w}$ & $\begin{array}{l}V_{E x p} \\
\text { and } \\
V_{F E A} \\
(\mathrm{kN})\end{array}$ & $(\mathrm{kN})$ & $\begin{array}{c}V_{A A} \\
(\mathrm{kN})\end{array}$ & $\begin{array}{c}V_{p} \\
(\mathrm{kN})\end{array}$ & $V / V_{E C}$ & $V / V_{A A}$ & $V / V_{p}$ \\
\hline G3-T2.0-S2-A0.5 & 295 & 0.56 & 80.6 & 119.7 & 38.7 & 118.7 & 0.67 & 2.08 & 0.68 \\
\hline G3-T2.0-S3-A0.5 & 295 & 0.56 & 93.2 & 119.6 & 38.7 & 118.6 & 0.78 & 2.41 & 0.79 \\
\hline G3-T2.0-S4-A0.5 & 295 & 0.56 & 106.8 & 119.4 & 38.7 & 118.4 & 0.89 & 2.76 & 0.90 \\
\hline G3-T2.0-S5-A0.5 & 295 & 0.56 & 109.4 & 119.3 & 38.7 & 118.3 & 0.92 & 2.82 & 0.92 \\
\hline G3-T2.5-S2-A0.5 & 236 & 0.56 & 112.8 & 157.6 & 113.0 & 147.3 & 0.72 & 1.00 & 0.77 \\
\hline G3-T2.5-S3-A0.5 & 236 & 0.56 & 129.3 & 157.2 & 113.0 & 147.0 & 0.82 & 1.14 & 0.88 \\
\hline G3-T2.5-S4-A0.5 & 236 & 0.56 & 145.8 & 156.8 & 113.0 & 146.6 & 0.93 & 1.29 & 0.99 \\
\hline G3-T2.5-S5-A0.5 & 236 & 0.56 & 156.2 & 156.6 & 113.0 & 146.3 & 1.00 & 1.38 & 1.07 \\
\hline G3-T3.0-S2-A0.5 & 197 & 0.56 & 149.4 & 199.6 & 187.3 & 184.9 & 0.75 & 0.80 & 0.81 \\
\hline G3-T3.0-S3-A0.5 & 197 & 0.56 & 168.9 & 199.0 & 187.3 & 184.3 & 0.85 & 0.90 & 0.92 \\
\hline G3-T3.0-S4-A0.5 & 197 & 0.56 & 183.3 & 198.5 & 187.3 & 183.8 & 0.92 & 0.98 & 1.00 \\
\hline G3-T3.0-S5-A0.5 & 197 & 0.56 & 192.0 & 198.2 & 187.3 & 183.5 & 0.97 & 1.03 & 1.05 \\
\hline G3-T6.0-S2-A0.5 & 98 & 0.56 & 432.0 & 545.9 & 500.9 & 487.0 & 0.79 & 0.86 & 0.89 \\
\hline G3-T6.0-S3-A0.5 & 98 & 0.56 & 443.6 & 544.6 & 500.9 & 485.6 & 0.81 & 0.89 & 0.91 \\
\hline G3-T6.0-S4-A0.5 & 98 & 0.56 & 454.6 & 543.3 & 500.9 & 484.3 & 0.84 & 0.91 & 0.94 \\
\hline G3-T6.0-S5-A0.5 & 98 & 0.56 & 472.6 & 541.1 & 500.9 & 482.2 & 0.87 & 0.94 & 0.98 \\
\hline G3-T1.5-S2-A1.0 & 393 & 1.11 & 41.4 & 46.5 & 6.5 & 53.1 & 0.89 & 6.37 & 0.78 \\
\hline G3-T1.5-S3-A1.0 & 393 & 1.11 & 49.2 & 46.4 & 6.5 & 53.0 & 1.06 & 7.57 & 0.93 \\
\hline G3-T1.5-S4-A1.0 & 393 & 1.11 & 57.4 & 46.3 & 6.5 & 52.9 & 1.24 & 8.83 & 1.08 \\
\hline G3-T1.5-S5-A1.0 & 393 & 1.11 & 65.5 & 46.2 & 6.5 & 52.8 & 1.42 & 10.08 & 1.24 \\
\hline G3-T2.0-S2-A1.0 & 295 & 1.11 & 61.7 & 66.2 & 15.4 & 73.3 & 0.93 & 4.01 & 0.84 \\
\hline G3-T2.0-S3-A1.0 & 295 & 1.11 & 73.1 & 66.0 & 15.4 & 73.0 & 1.11 & 4.75 & 1.00 \\
\hline G3-T2.0-S4-A1.0 & 295 & 1.11 & 84.9 & 65.7 & 15.4 & 72.8 & 1.29 & 5.51 & 1.17 \\
\hline G3-T2.0-S5-A1.0 & 295 & 1.11 & 89.6 & 65.6 & 15.4 & 72.6 & 1.37 & 5.82 & 1.23 \\
\hline G3-T2.5-S2-A1.0 & 236 & 1.11 & 85.6 & 88.5 & 30.1 & 93.6 & 0.97 & 2.84 & 0.91 \\
\hline G3-T2.5-S3-A1.0 & 236 & 1.11 & 100.3 & 88.0 & 30.1 & 93.2 & 1.14 & 3.33 & 1.08 \\
\hline G3-T2.5-S4-A1.0 & 236 & 1.11 & 113.3 & 87.5 & 30.1 & 92.7 & 1.29 & 3.77 & 1.22 \\
\hline G3-T2.5-S5-A1.0 & 236 & 1.11 & 119.8 & 87.3 & 30.1 & 92.5 & 1.37 & 3.98 & 1.30 \\
\hline G3-T3.0-S2-A1.0 & 197 & 1.11 & 113.1 & 113.4 & 52.0 & 113.9 & 1.00 & 2.18 & 0.99 \\
\hline G3-T3.0-S3-A1.0 & 197 & 1.11 & 130.2 & 112.6 & 52.0 & 113.1 & 1.16 & 2.50 & 1.15 \\
\hline G3-T3.0-S4-A1.0 & 197 & 1.11 & 140.0 & 112.1 & 52.0 & 112.6 & 1.25 & 2.69 & 1.24 \\
\hline G3-T3.0-S5-A1.0 & 197 & 1.11 & 145.5 & 111.8 & 52.0 & 112.3 & 1.30 & 2.80 & 1.30 \\
\hline G3-T6.0-S2-A1.0 & 98 & 1.11 & 327.1 & 317.1 & 481.7 & 279.7 & 1.03 & 0.68 & 1.17 \\
\hline G3-T6.0-S3-A1.0 & 98 & 1.11 & 334.8 & 315.8 & 481.7 & 278.4 & 1.06 & 0.70 & 1.20 \\
\hline G3-T6.0-S4-A1.0 & 98 & 1.11 & 343.3 & 314.3 & 481.7 & 276.9 & 1.09 & 0.71 & 1.24 \\
\hline G3-T6.0-S5-A1.0 & 98 & 1.11 & 354.5 & 312.2 & 481.7 & 274.8 & 1.14 & 0.74 & 1.29 \\
\hline \multicolumn{7}{|c|}{ Mean, $U_{m}$} & 0.99 & 2.96 & 1.02 \\
\hline \multicolumn{7}{|c|}{$\mathrm{COV}, U_{p}$} & 0.210 & 0.791 & 0.169 \\
\hline \multicolumn{7}{|c|}{ Reliability index, $\beta_{1}$} & 1.80 & 2.13 & 2.67 \\
\hline & & & & \multicolumn{3}{|c|}{ Resistance factor, $\phi_{v l}$} & 0.91 & 0.80 & 0.80 \\
\hline & & & & \multicolumn{3}{|c|}{ Reliability index, $\beta_{2}$} & 2.47 & 2.13 & 2.67 \\
\hline & & & & \multicolumn{3}{|c|}{ Resistance factor, $\phi_{v 2}$} & 0.80 & 0.80 & 0.80 \\
\hline
\end{tabular}


Table 11. Comparison of Numerical Results with Design Strengths (Group 4)

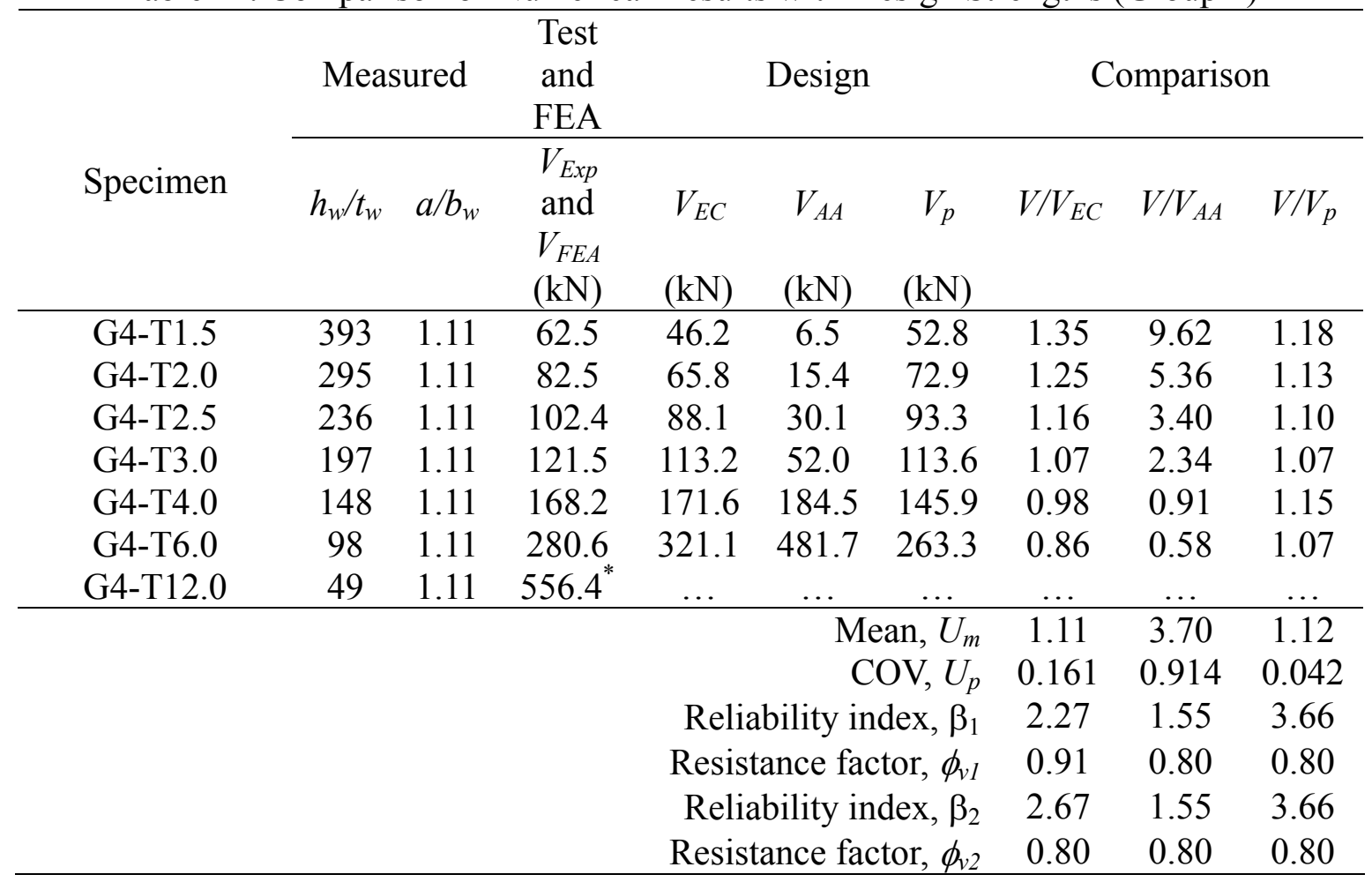

Note: * Failed by bending, hence not compared with the shear design resistance.

\section{COMPARISON OF EXPERIMENTAL AND NUMERICAL RESULTS WITH PROPOSED DESIGN STRENGTHS}

The unfactored shear design resistances $\left(V_{p}\right)$ calculated using the modified design method were compared with the test results $\left(V_{E x p}\right)$ and the shear strengths $\left(V_{F E A}\right)$ predicted by the FEA. The proposed design strengths were calculated using the measured cross-section dimensions and measured material properties. The resistance facto $\phi_{v}=0.8$ was obtained from the reliability analysis. The load combination of $1.2 \mathrm{DL}+1.6 \mathrm{LL}$ was used to determine the reliability indices $\left(\beta_{1}\right.$ and $\beta_{2}$ ).

The proposed design strengths are generally conservative and reliable. The maximum mean value of the load ratio is 1.25 with the corresponding COV of 0.078 and the value of $\beta_{1}=\beta_{2}=4.05$ for the Group 2, as shown in Table 9. The minimum mean value of the load ratio is 1.02 with the corresponding COV of 0.169 and the value of $\beta_{1}=\beta_{2}=2.67$ for the Group 3, as shown in Table 10 . The reliability indices $\left(\left(\beta_{1}\right.\right.$ and $\left.\beta_{2}\right)$ are greater than the target value for all specimens. It is shown that the proposed design method provides more accurate and reliable predictions than the current design rules for aluminum alloy plate girders subjected to shear force. 


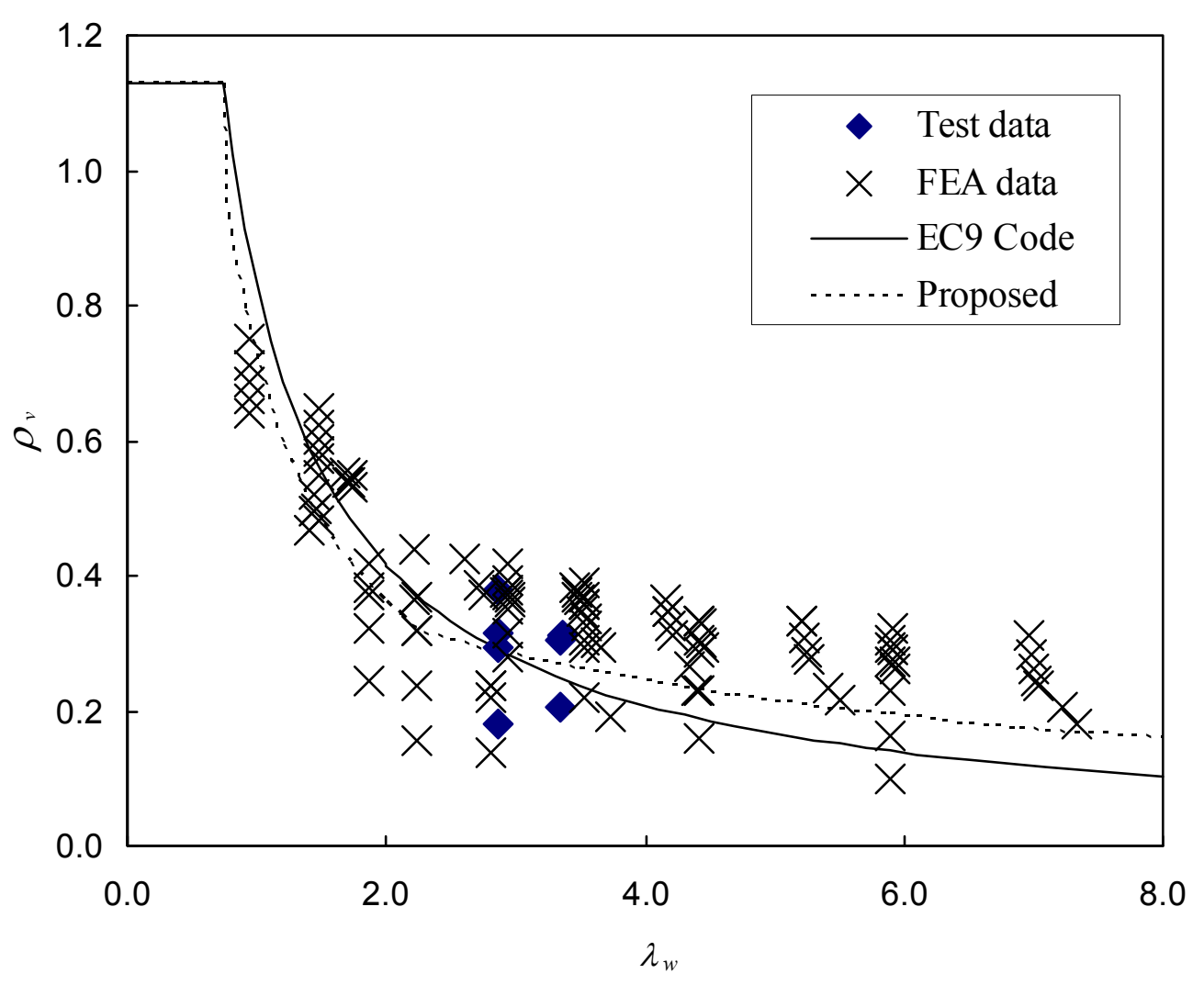

Figure 11. Factor $\rho_{v}$ for Shear Buckling

\section{CONCLUSIONS}

Numerical investigation of welded aluminum alloy plate girders with end posts having a single plate subjected to shear force has been presented in this paper. A finite element model including geometric and material non-linearities has been developed and verified against experimental results. The heat affected zone (HAZ) softening due to welding of the aluminum alloy is also considered in the finite element model. The finite element model closely predicted the shear behaviour of aluminum alloy plate girders compared with the test results. Hence, parametric study was carried out to study the effects of cross-section geometries on the shear resistance of aluminum alloy plate girders with non-rigid end post.

The appropriateness of the shear resistance design rules in the current European Code and American Specification for aluminum structures has been examined. The test results and the shear resistance predicted by the finite element analysis were compared with the design strengths obtained using the current European Code and American Specification for aluminum structures. It is shown that the design strengths predicted by the European Code are generally conservative but not reliable. The design strengths predicted by the American Specification are generally very conservative. Therefore, a design method for shear resistance of aluminum alloy plate girders has been proposed by small modifications to the design rules in the current European Code. It is shown that the proposed design strengths are generally conservative and reliable. It is also shown that the proposed design method provides more accurate and reliable predictions than the current design rules in the European Code and American Specification for welded aluminum alloy plate girders subjected to shear force. 


\section{ACKNOWLEDGEMENTS}

The research work described in this paper were supported by the Chinese National Natural Science Foundation (Project No. 51108337), Shanghai Municipal Natural Science Foundation (Project No. 11ZR1439400) and The University of Hong Kong under the seed funding program for basic research.

\section{NOTATION}

The following symbols are used in this paper:

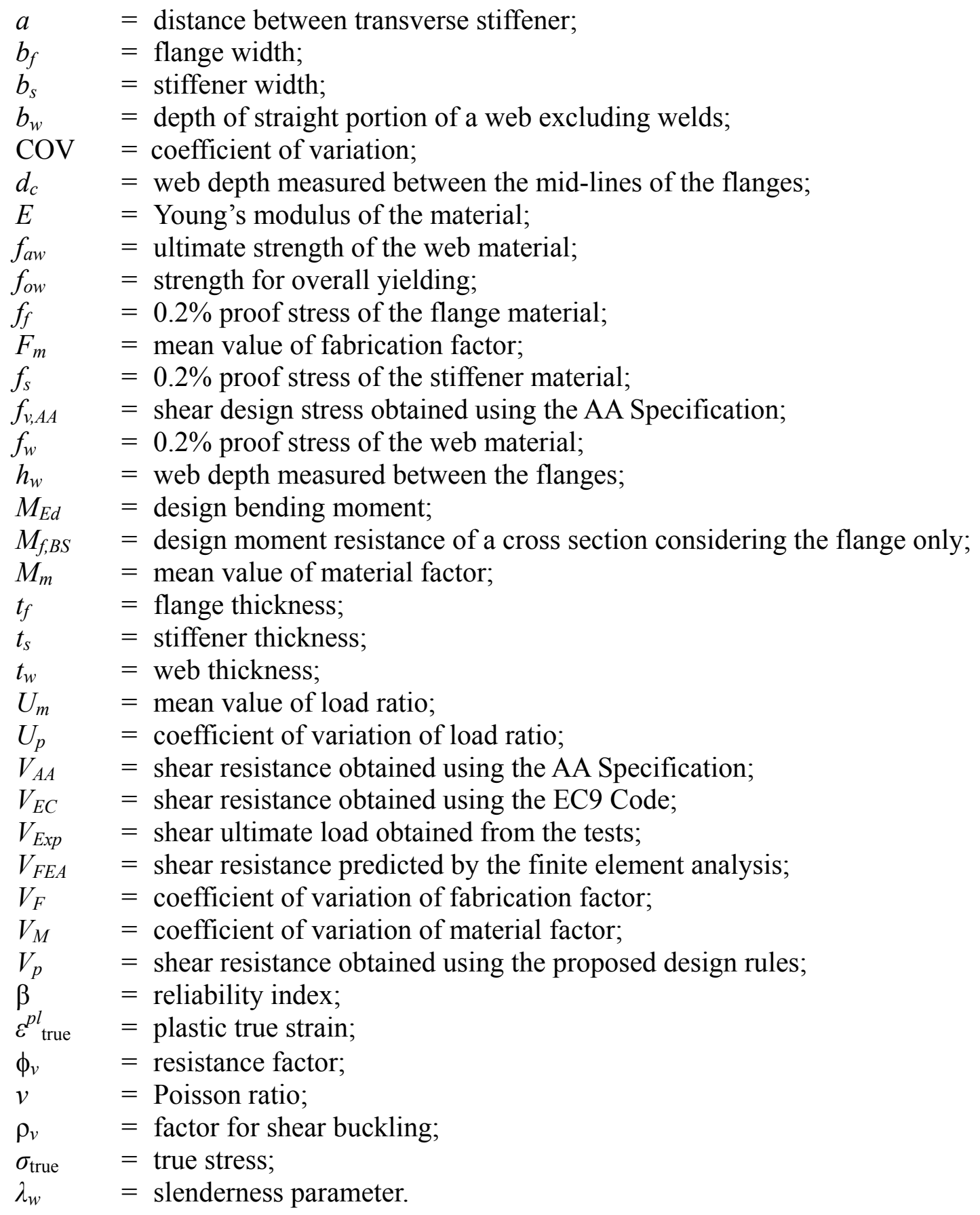




\section{REFERENCES}

[1] Evans, H.R., "Longitudinally and Transversely Reinforced Plate Girders", In Plated Structures, Stability and Strength, Ch. 1, Applied Science Publishers, London, 1983.

[2] Tang, K.H. and Evans, H.R., "Transverse Stiffeners for Plate Girder Webs - An Experimental Study”, Journal of Constructional Steel Research, 1984, Vol. 4, No. 4, pp. 253-280.

[3] Narayanan, R. and Der-Avanessian, N.G.V., "Analysis of Late Girders with Perforated Webs." Thin-walled Structures, 1986, Vol. 4, No. 5, pp. 363-380.

[4] Sulyok, M. and Galambos, T.V., "Evaluation of web buckling test results on welded beams and plate girders subjected to shear." Engineering Structures, 1996, Vol. 18, No. 6, pp. 459-464.

[5] Real, E., Mirambell, E. and Estrada, I., "Shear Response of Stainless Steel Plate Girders", Engineering Structures, 2007, Vol. 29, No. 7, pp. 1626-1640.

[6] Alinia, M.M., Shakiba, M. and Habashi, H.R., "Shear Failure Characteristics of Steel Plate Girders", Thin-walled Structures, 2009, Vol. 47, No. 12, pp. 1498-1506.

[7] Evans, H.R. and Hamoodi, M.J., "The Collapse of Welded Aluminum Plate Girders - An Experimental Study”, Thin-walled Structures, 1987, Vol. 5, No. 4, pp. 247-275.

[8] Cheng, M., Shi, Y.J. and Wang, Y.Q., "Shear Resistance of Aluminum Plate Girders", In : Proc., $6^{\text {th }}$ International Conference on Steel and Aluminum Structures, Oxford Brookes University, 2007.

[9] Kissell, J.R. and Ferry, R.L., "Aluminum Structures - A Guide to their Specifications and Design”, $2^{\text {nd }}$ ed. New York: Wiley, 2002.

[10] ABAQUS Standard User's Manual, Hibbitt, Karlsson and Sorensen, Inc. Vols. 1-3, Version 6.7, USA, 2007.

[11] Lam, H.C., "The Analysis of Aluminum Plate Girders", PhD Thesis, University of Wales, College of Cardiff, 1993.

[12] EC9, Eurocode 9 : Design of Aluminum Structures - Part 1.1 : General Structural Rules, BS EN 1999-1-1:2007, European Committee for Standardization, 2007.

[13] AA, Aluminum Design Manual, The Aluminum Association. Washington, D.C, 2005.

[14] ASCE, Minimum Design Loads for Buildings and Other Structures, ASCE Standard 7-05, American Society of Civil Engineers Standard, New York, 2005. 